\title{
CHAPTER 4.3.
}

\section{PRACTICAL AND OPERATIONAL GENETIC SEXING SYSTEMS BASED ON CLASSICAL GENETIC APPROACHES IN FRUIT FLIES, AN EXAMPLE FOR OTHER SPECIES AMENABLE TO LARGE-SCALE REARING FOR THE STERILE INSECT TECHNIQUE}

\author{
G. FRANZ, K. BOURTZIS AND C. CÁCERES
}

FAO/IAEA Agriculture and Biotechnology Laboratories, A-2444 Seibersdorf, Austria

Email: C.E.Caceres-Barrios@iaea.org

\section{TABLE OF CONTENTS}

1. INTRODUCTION

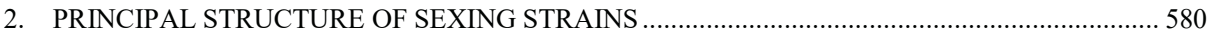

2.1. Mutations for Large-Scale Separation of Sexes ................................................................. 581

2.1.1. Sex Separation versus Female Killing ................................................................. 581

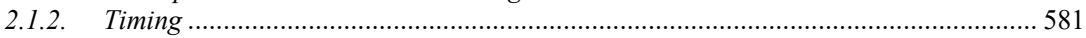

2.1.3. Physical or Chemical Treatment to Kill Females ..................................................... 581

2.1.4. General Considerations....................................................................................... 582

2.1.5. Temperature-Sensitive Period in Individuals Homozygous for the tsl Mutation ......... 582

2.1.6. Maternal Effect in Individuals Heterozygous for the tsl Mutation ............................ 582

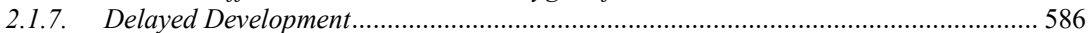

2.1.8. Unwanted Recombinants and Filter Rearing System .......................................... 586

2.1.9. Large-Scale Temperature Treatment of Embryos ................................................. 587

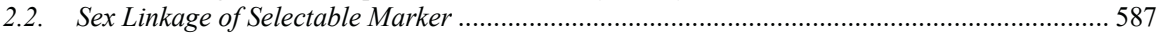

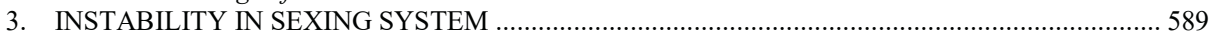

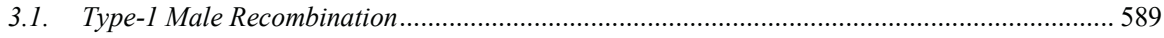

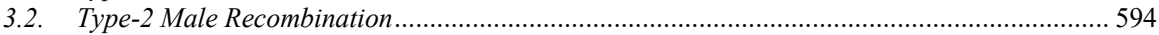

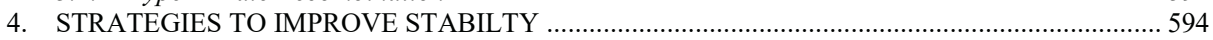

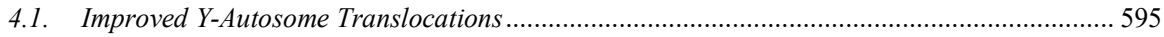

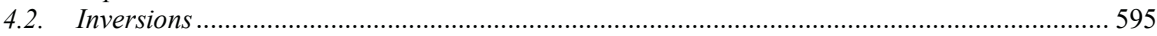

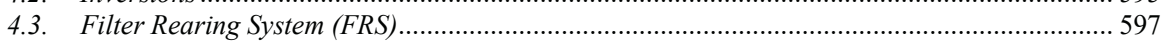




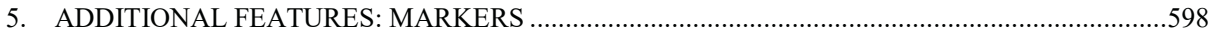

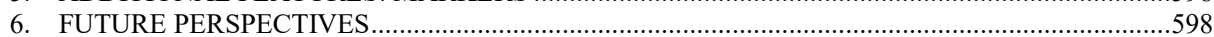

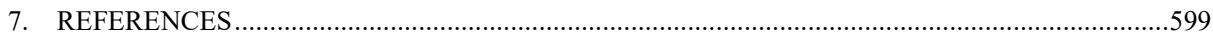

\section{SUMMARY}

Through genetic and molecular manipulations, strains can be developed that are more suitable for the sterile insect technique (SIT). In this chapter the development of genetic sexing strains (GSSs) using classical genetic approaches is described, while the development of GSSs using molecular approaches is discussed by Häcker et al. (this volume). GSSs increase the effectiveness of area-wide integrated pest management (AWIPM) programmes that use the SIT by enabling the large-scale production and release of only sterile males, and generally increasing sterile-male effectiveness when competing for wild females in the absence of sterile females. For species that transmit disease, the removal of females is mandatory. GSSs have been developed for several species, including Tephritidae and mosquitoes. For the Mediterranean fruit fly Ceratitis capitata (Wiedemann) and the Mexican fruit fly Anastrepha ludens (Loew), genetic sexing systems have been developed, and they have been shown to be stable enough at large-scale mass-rearing levels to be used in operational programmes for extended periods of time. In this chapter, the basic principle of translocation-based sexing strains is described, and Mediterranean fruit fly and Mexican fruit fly strains are used as examples to indicate the problems encountered in developing and using such strains. Furthermore, the strategies used to solve these problems are described.

\section{INTRODUCTION}

The sterile insect technique (SIT) is an increasingly important component of area-wide integrated pest management (AW-IPM) programmes for certain key insect pest species (Table 1). The application of the SIT in operational programmes, and its expansion to additional pest species, continues to reveal areas where technology can improve the SIT. An example of using improved technology is the transfer of genetic sexing technology to Mediterranean fruit fly Ceratitis capitata (Wiedemann) (Rendón et al. 2000, 2004), and more recently to the Mexican fruit fly Anastrepha ludens (Loew) (Orozco et al. 2013; Zepeda-Cisneros et al. 2014) programmes. In future, in view of their important benefits, it is expected that such strains will be required for many other insect species of agricultural, veterinary or human health importance. Beyond application for the SIT, genetic sexing technology has been applied to natural enemies and to the silkworm Bombyx mori (L.). In the latter case, males produce more silk. Wautosome translocation sexing strains, based on a cocoon marker, were developed (Nagaraju 2002) and, in India, are reared at a male-only production level of 125 million per week (J. Nagaraju, personal communication).

Based on the reproductive biology of most insects, and on the basic principle underlying the SIT, it is clear that generally only released sterile males are important for this technique to be effective. Wild females determine the population size of the next generation, but wild males, or more precisely the sperm they produce, are present in such great excess that it would be necessary to remove about $99 \%$ of all wild sperm before obtaining a significant reduction in the size of the next generation (Koyama et al. 1984; Barclay and Hendrichs 2014). Sterility is introduced into a wild population only through sterile males, even when they are released together with sterile females. Recognizing this principle, the SIT was initially called the "sterile-male method" (Knipling 1959). However, at that time, the only AW-IPM programme integrating the SIT was against the New World screwworm Cochliomyia hominivorax (Coquerel), 
and both sexes were released. The name was meant to highlight the fact that only the sterile males are the active agent in the SIT. As demonstrated very clearly for the Mediterranean fruit fly by McInnis et al. (1994) and Rendón et al. (2000, 2004), bisexual releases are far less effective than male-only releases in introducing sterility into a wild population, and this will probably apply to many pest species. The obvious reason is that the released sterile males and females tend to mate with each other. As a result, the proportion of matings between sterile males and wild females is reduced, and less sterility is introduced into the wild population.

Table 1. Approximate worldwide maximum mass-rearing capacities for SIT application achieved at one time for different species (some data from FAO/IAEA DIR-SIT 2020)

\begin{tabular}{|c|c|c|}
\hline Species & $\begin{array}{l}\text { Maximum } \\
\text { production } \\
\text { reached in } \\
\text { millions per } \\
\text { week }\end{array}$ & $\begin{array}{l}\text { Genetic trait that defines } \\
\text { the sexing strategy }\end{array}$ \\
\hline \multicolumn{3}{|l|}{ Screwworm flies } \\
\hline $\begin{array}{l}\text { New World screwworm Cochliomyia hominivorax } \\
\text { (Coquerel) }\end{array}$ & 500 & No \\
\hline Old World screwworm Chrysomya bezziana (Villeneuve) & 6 & No \\
\hline \multicolumn{3}{|l|}{ Fruit flies } \\
\hline Mediterranean fruit fly Ceratitis capitata (Wiedemann) & $\begin{array}{l}3500 \\
\text { (only } \\
\text { males) }\end{array}$ & $\begin{array}{l}\text { Y-autosome translocation, } \\
\text { using a temperature- } \\
\text { sensitive lethal }(\text { tsl })\end{array}$ \\
\hline Mexican fruit fly Anastrepha ludens (Loew) & $\begin{array}{c}250 \\
\text { (only } \\
\text { males) }\end{array}$ & $\begin{array}{l}\text { Y-autosome translocation, } \\
\text { pupal colour separation }\end{array}$ \\
\hline Melon fly Zeugodacus cucurbitae (Coquillett) & 200 & $\begin{array}{l}\text { No (Y-autosome } \\
\text { translocation, pupal colour } \\
\text { separation }^{1} \text { ) }\end{array}$ \\
\hline West Indian fruit fly Anastrepha obliqua (Macquart) & 60 & No \\
\hline Oriental fruit fly Bactrocera dorsalis (Hendel) & 50 & $\begin{array}{l}\text { No (Y-autosome } \\
\text { translocation, pupal colour } \\
\text { separation }^{2} \text { ) }\end{array}$ \\
\hline Queensland fruit fly Bactrocera tryoni (Froggatt) & 15 & $\mathrm{No}^{3}$ \\
\hline Bactrocera carambolae Drew and Hancock & & $\begin{array}{l}\text { (See Häcker et al., this } \\
\text { volume) }\end{array}$ \\
\hline Sapote fruit fly Anastrepha serpentina (Wiedemann) & 5 & No \\
\hline $\begin{array}{l}\text { South American fruit fly Anastrepha } \\
\text { fraterculus(Wiedemann) (species 1) }\end{array}$ & 2 & $\begin{array}{l}\text { No (Y-autosome } \\
\text { translocation, pupal colour } \\
\text { separation }^{4} \text { ) }\end{array}$ \\
\hline Olive fruit fly Bactrocera oleae (Rossi) & $<1$ & No \\
\hline Malaysian fruit fly Bactrocera latifrons (Hendel) & $<1$ & No \\
\hline
\end{tabular}


Table 1. Continued

\begin{tabular}{|c|c|c|}
\hline Species & $\begin{array}{l}\text { Maximum } \\
\text { production } \\
\text { reached in } \\
\text { millions per } \\
\text { week }\end{array}$ & $\begin{array}{l}\text { Genetic trait that defines } \\
\text { the sexing strategy }\end{array}$ \\
\hline \multicolumn{3}{|l|}{ Onion maggot } \\
\hline Onion maggot Delia antiqua (Meigen) & 7.5 & No \\
\hline \multicolumn{3}{|l|}{ Moths } \\
\hline Pink bollworm Pectinophora gossypiella (Saunders) & 150 & No \\
\hline False codling moth Thaumatotibia leucotreta (Meyrick) & 30 & No \\
\hline Codling moth Cydia pomonella (L.) & 14 & No \\
\hline Gypsy moth Lymantria dispar (L.) & 1 & $\mathrm{No}^{5}$ \\
\hline Carob moth Ectomyelois ceratoniae (Zeller) & $<1$ & No \\
\hline \multicolumn{3}{|l|}{ Tsetse flies } \\
\hline Glossina pallidipes Austen & $<1$ & $\begin{array}{l}\text { No (Manual, sex-specific, } \\
\text { time of emergence }{ }^{6} \text { ) }\end{array}$ \\
\hline Glossina palpalis gambiensis Vanderplank & $<1$ & $\begin{array}{l}\text { No (Manual, sex-specific, } \\
\text { time of emergence }{ }^{6} \text { ) }\end{array}$ \\
\hline Glossina fuscipes fuscipes Newstead & $<1$ & $\begin{array}{l}\text { No (Manual, sex-specific, } \\
\text { time of emergence }{ }^{6} \text { ) }\end{array}$ \\
\hline \multicolumn{3}{|l|}{ Mosquitoes } \\
\hline Anopheles albimanus Wiedemann & $<1$ & $\begin{array}{l}\text { Pupal size, Y-autosome } \\
\text { translocation, propoxur } \\
\text { resistance }\end{array}$ \\
\hline Aedes aegypti (L.) & $<1$ & \multirow{2}{*}{$\begin{array}{l}\text { No (Sex separation by } \\
\text { pupal size) }\end{array}$} \\
\hline Aedes albopictus (Skuse) & $<10$ & \\
\hline Anopheles arabiensis Patton & $<1$ & $\begin{array}{l}\text { Y-autosome translocation, } \\
\text { dieldrin resistance }\end{array}$ \\
\hline
\end{tabular}

\footnotetext{
${ }^{1} \mathrm{~A}$ sexing strain is available, but is not reared on a large scale (McInnis et al. 2004).

${ }^{2} \mathrm{~A}$ sexing strain is available, but is not reared on a large scale (McCombs and Saul 1995).

${ }^{3}$ A strain was developed where the females carry a wing mutation (bent wing), and are thereby disabled, so effectively only males are active in the field (Meats et al. 2002). This strain has not yet been used in large-scale programmes.

${ }^{4} \mathrm{~A}$ sexing strain is available, but is not reared on a large scale (Meza et al. 2019).

${ }^{5}$ IAEA 2008.

${ }^{6}$ Infrared sex separation of pupae for some species; it has not yet been used in large-scale programmes (Dowell et al. 2005).
} 
To address this problem, it was suggested that strains producing only males should be developed (Whitten 1969; Hendrichs et al. 1995). Besides improved effectiveness in the field, it was expected that mass-rearing costs would be reduced significantly, but this is not always the case (Caceres 2002; Caceres et al. 2004). Nevertheless, significant cost reductions can be achieved in the post-production processes. Only half the volume of pupae is handled for marking, irradiation, transport, emergence, feeding to maturation, and release activities, and the cost of monitoring is reduced significantly, especially in combination with female-specific traps (Epsky et al. 1999; Vreysen, this volume).

Another very important consideration is that, in some cases, sterile females simply cannot be released. Fruit fly females may cause damage from "sterile stings" in certain fruit types, females of biting flies reduce meat production in livestock, and females of bloodsucking species may transmit disease (Lance and McInnis, this volume; Lees et al., this volume).

For a few species, natural characters can be used for large-scale separation of the sexes, e.g. sex-specific pupal-size differences (Dame et al. 1974; Papathanos et al. 2018; Zacarés et al. 2018), and sex-specific differences in the timing of adult emergence, e.g. tsetse fly Glossina austeni Newstead (Opiyo et al. 2000; Parker, Mamai et al., this volume). For species where only females suck blood, it is possible to feed them with a toxic substance, and then release the males (Yamada et al. 2013). However, the biology of most species does not permit sex separation on the scale required for the SIT and, therefore, specific sex separation strains have to be developed. To date, this has been achieved using Mendelian genetics, specific mutations, and chromosome rearrangements, as well as, more recently, using molecular-based approaches (Häcker et al., this volume).

Genetic sexing strains (GSSs) have been developed for several species, including the Australian sheep blow fly Lucilia cuprina (Wiedemann) (Whitten 1969), and recently the South American fruit flies (Meza et al. 2019), using the same basic principle of sex-specific linkage of a selectable marker. However, only for Anopheles albimanus Wiedemann (Seawright et al. 1978; Bailey et al. 1980), C. capitata (Franz et al. 1994), and A. ludens (Zepeda-Cisneros et al. 2014) were GSSs developed to the point where they could be mass-reared at levels required for AW-IPM programmes integrating the SIT (Table 1), and only in C. capitata and A. ludens was the sexing system improved enough for large-scale application over extended periods of time.

As described below, constructing a basic sexing strain is rather trivial. However, such "prototype" strains do not normally show the characteristics that are essential for successful long-term integration of the SIT as part of area-wide programmes. These characteristics include aspects of feasibility and economy, i.e. using the appropriate type of sex-separation mechanism, as well as productivity and stability, i.e. the overall genetic structure of the strain. To transfer a sexing system from an experimental laboratory to a mass-rearing facility requires very intensive research into the genetic behaviour of the sexing system. This approach is usually supplemented by incorporating appropriate modifications that provide sustainability for extended periods under large mass-rearing conditions. This requires basic genetic knowledge of the species involved, and until now this has been achieved for only very few pest species. 
Even though GSSs for operational AW-IPM programmes releasing sterile insects are available for the Mediterranean and Mexican fruit flies, nevertheless only the Mediterranean fruit fly strains have been analysed sufficiently to permit general conclusions; this species is referred to extensively in this chapter. It illustrates the problems encountered and modifications introduced to obtain improved sexing strains that are advanced enough to allow a current worldwide production of about 3500 million male flies per week (Table 1).

The lessons learned from this species can very likely be extrapolated to all translocation-based strategies for other species and, to some extent, to new methods using molecular biology. The enormous numbers of insects that must be reared under relatively stressful conditions dictate that even extremely rare genetic or molecular phenomena can threaten the integrity of the sexing system.

\section{PRINCIPAL STRUCTURE OF SEXING STRAINS}

All GSSs developed to date are based on the same principle, and require two separate components (Fig. 1) (Whitten 1969; Franz and Kerremans 1994):

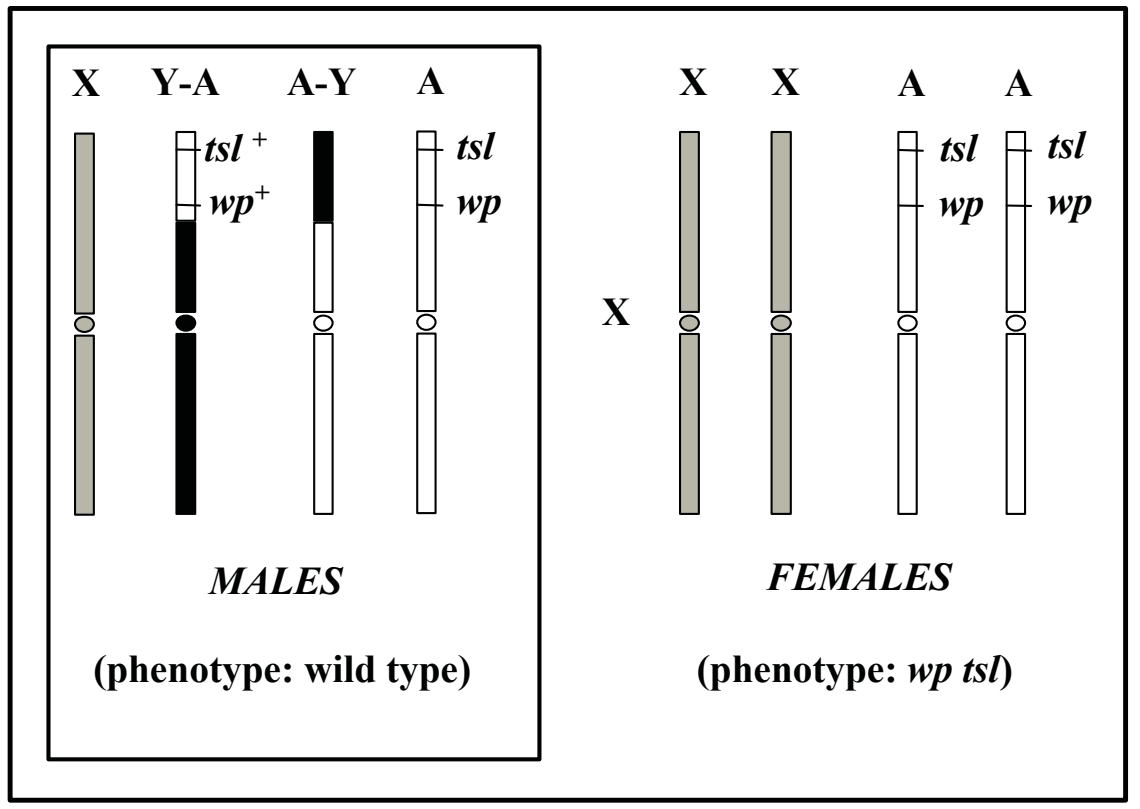

Figure 1. Basic structure of GSS carrying Y-autosome translocation linking normal "wild-type" alleles of the selectable markers white pupae (wp) and temperature-sensitive lethal (tsl) to the male sex. $Y$-A: translocation fragment carrying $Y$ chromosomal centromere, $A-Y$ : reciprocal translocation fragment carrying autosomal centromere, $X: X$ chromosome, A: autosome. 
- Mutation that can be used as a selectable marker for sex separation (a list of potential selectable markers is given in Table 2 in Robinson 2002),

- Y-autosome translocation to link the inheritance of this mutation to sex.

In the Mediterranean fruit fly, and probably also in many other pest Diptera, the $\mathrm{Y}$ chromosome carries a dominant Maleness factor (Willhoeft and Franz 1996). To construct a GSS, the wild-type allele of the selectable marker is physically linked to this chromosome via a Y-autosome translocation (Fig. 1). In the resulting strain, the males are heterozygous (normal "wild-type" phenotype), and the females homozygous for the selectable marker and thus express the mutation, and can be separated from males. Y-autosome translocations are induced by irradiation, followed by a genetic screen that is based either on the inherited sterility associated with translocations or on a mutation to detect male-linked inheritance. The former method can be used in all species, even where no, or only very limited, genetic information is available. Not all translocations are equally appropriate for use in a GSS, e.g. translocations involving multiple autosomes have a high level of sterility. As outlined below, the stability and productivity of a strain depend crucially on the structure of the translocation.

\subsection{Mutations for Large-Scale Separation of Sexes}

The choice of a suitable selectable marker involves decisions regarding the feasibility and economics of the resulting sexing mechanism. In this context, several criteria must be considered.

\subsubsection{Sex Separation versus Female Killing}

Killing females is the best option, except for special cases where females are needed to maintain the colony (species with a low reproductive capacity, such as tsetse flies).

\subsubsection{Timing}

To minimize rearing costs, females should be killed as early as possible during development. Timing also determines the stage, and corresponding amount of biomass, during which the females must be killed, and this has an effect on the practicality, cost, and accuracy of the treatment, e.g. for fruit flies large numbers of eggs can be treated more easily than large numbers of larvae or pupae.

\subsubsection{Physical or Chemical Treatment to Kill Females}

The egg stage is the most practical stage, but in most cases chemicals cannot penetrate the eggshell, and a selectable marker that responds to physical treatment (e.g. temperature) is required. If only selectable markers that are sensitive to chemicals are available, the larval stage is the earliest possible stage for sexing. The use of chemicals raises additional points: cost of the chemical, human toxicity (to workers), accessibility to the chemical by feeding larvae (solubility, distribution, and stability in the diet), effect on symbionts or bacteria in the diet, and disposal of spent diet containing the chemical. 


\subsubsection{General Considerations}

It is important also to know the accuracy of the sexing mechanism, the additional costs for equipment, chemicals, etc., and the reduced productivity (in comparison with a standard strain). The accuracy of eliminating females should be close to $100 \%$, but the selectable marker should not negatively affect the viability and productivity of mutant females in the colony.

Choosing the right selectable marker is a vital decision. Several different markers for the Mediterranean fruit fly are available (Robinson 2002). However, most of them are not ideal for large-scale application. Current GSSs for this species carry two mutations, temperature-sensitive lethal (tsl) (Franz et al. 1994) that is used to eliminate females, and the closely linked mutation white pupae (wp) (Rössler 1979) used as a visible marker. The $t s l$ mutation has certain biological properties that impact on its usefulness and also on the procedures required for mass-rearing or sexing.

\subsubsection{Temperature-Sensitive Period in Individuals Homozygous for the tsl Mutation} In a GSS, females are homozygous for the $t s l$ mutation. The standard protocol to test temperature sensitivity is a 24-hour treatment at temperatures from 31 to $35^{\circ} \mathrm{C}$, compared with the control at $25^{\circ} \mathrm{C}$. To determine the sensitive period of the tsl mutation, eggs are collected for 1 hour, and temperature tests done at different stages of development. As shown in Fig. 2A, homozygous $t s l$ individuals are very sensitive to temperature during the embryonic stage, and to a lesser extent during moulting from first- to second-instar, and from second- to third-instar, larvae. Fig. $2 \mathrm{~B}$ shows the results of temperature tests with pupae of known age. The pupae are also sensitive to temperature, especially during the first 3 days.

Additional tests were done with adults, maintaining the cages at 25, 28, 31, and $34^{\circ} \mathrm{C}$, and daily mortality was measured. In the $t s l$ homozygous strain, significant mortality was observed already at $28^{\circ} \mathrm{C}$ (Fig. 3).

In conclusion, temperature sensitivity is strongest during the egg stage, and elimination of homozygous $t s l$ individuals is achieved by incubating eggs at $34^{\circ} \mathrm{C}$ for 24 hours. Secondly, later stages are also temperature sensitive. Therefore, the temperature during mass-rearing must be carefully controlled to prevent damage to the tsl homozygous females. Thirdly, even though the sensitivity of the adults is a complication for mass-rearing, it also has a benefit in that any homozygous tsl individuals that escape will not be viable at elevated temperatures. This applies to any flies that may escape from a production facility, and to the few remaining females among the released sterile males.

\subsubsection{Maternal Effect in Individuals Heterozygous for the tsl Mutation}

In a GSS, the males are heterozygous for the tsl mutation, but does the presence of a wild-type allele completely suppress the sensitivity to temperature? Originally the temperature treatment to eliminate females was done relatively early during embryogenesis, i.e. eggs were collected for 24 hours, followed immediately by the $24-$ hour temperature treatment. However, this resulted in a reduced recovery of males. 


\section{Homozygous tsl strain}

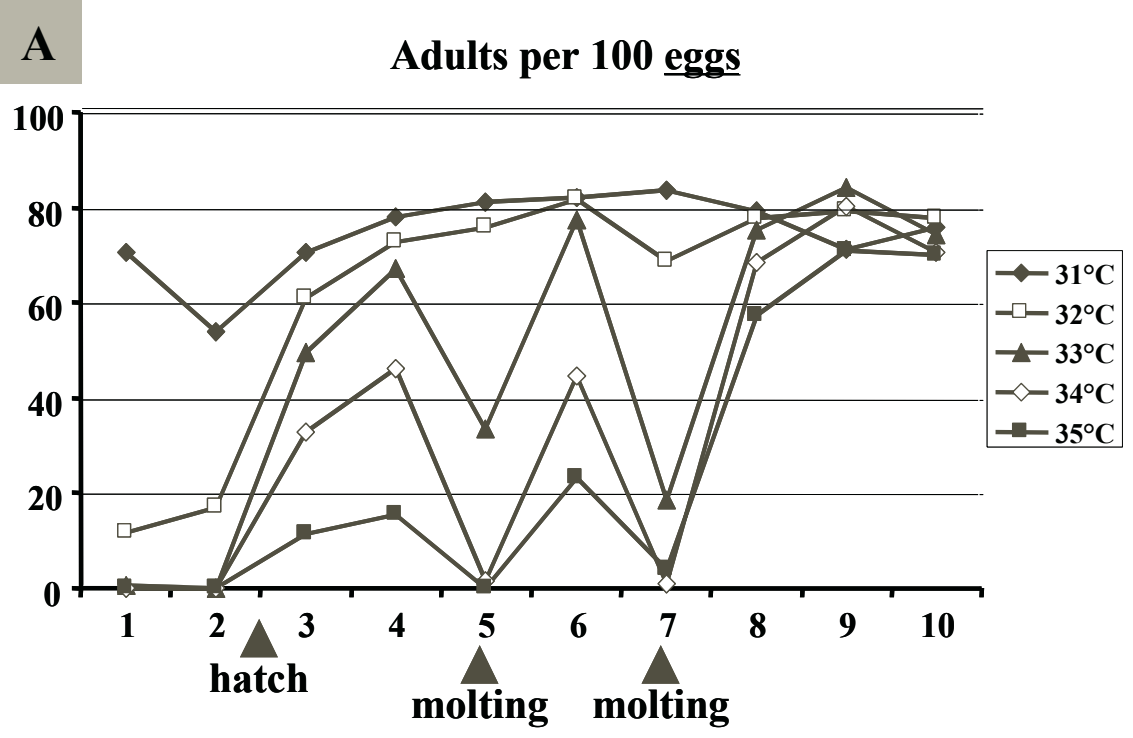

Treatment day (days after egg collection)

\section{B}

Adults per $100 \underline{\underline{\text { larvae }}}$

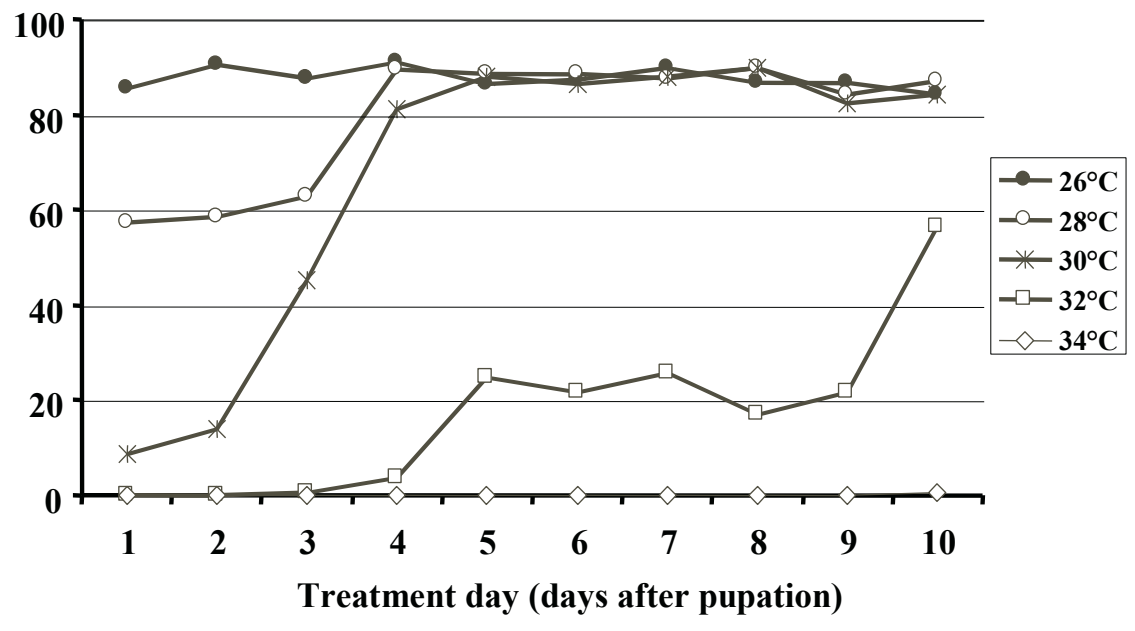

Figure 2. Temperature pulse experiments with homozygous tsl strain. Eggs (A) or pupae (B) were collected for 1 hour followed by temperature treatment during different days of development with temperatures indicated. 


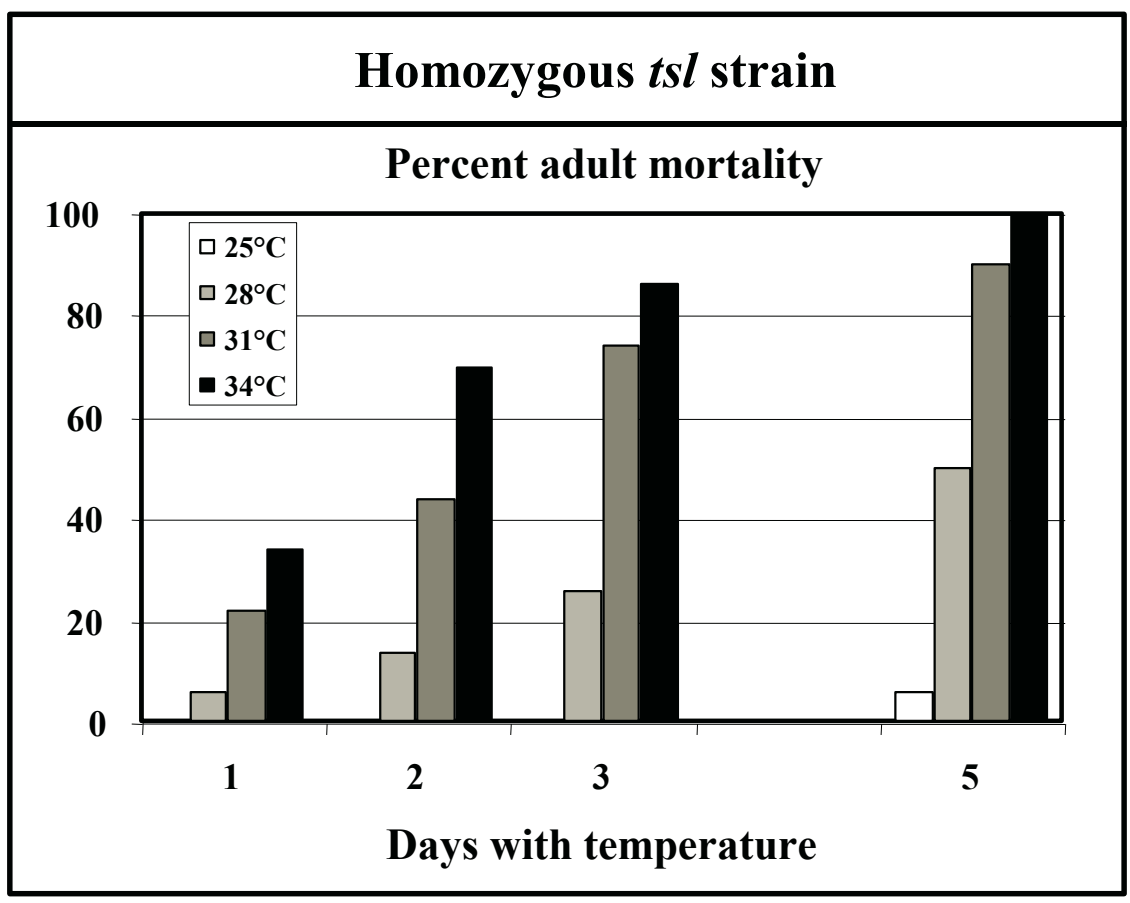

Figure 3. Temperature treatment of adults homozygous for tsl mutation. After emergence, adults were maintained constantly at temperatures indicated.

Tests of $F_{1}$ individuals from reciprocal crosses, between a wild-type strain and a homozygous $t s l$ strain, demonstrated that the temperature sensitivity of the $\mathrm{F}_{1}$ differed significantly, although in both cases the genetic constitution of the $F_{1}$ is identical $\left(t s l / t s l^{+}\right)$. Fig. 4B shows that, in the first cross (wild type $t s l^{+}$females and $t s l$ males), the $t s l^{+}$allele is completely dominant over the mutant allele, i.e. the same level of lethality is observed in $\mathrm{F}_{1}$ offspring as in a wild-type strain (Fig. 4A). However, in the reciprocal cross where homozygous $t s l$ females are used, a significant temperature sensitivity of the $\mathrm{F}_{1}$ offspring is observed (Fig. 4C).

This difference is due to a maternal effect. During the early stages of development, the embryo's own genome is inactive, and apparently it utilizes a $t s l$-gene product that it receives in the egg from the mother. Consequently, during these early stages of development, the embryo is dependent on the genotype of the mother, and in a GSS the mother is homozygous for the $t s l$. Only after activating their own genetic material are the heterozygous $t s l / t s l^{+}$males protected against elevated temperatures. Based on these findings, the temperature-treatment regime was modified, i.e. after collection, and before the treatment is applied, eggs are maintained at $25^{\circ} \mathrm{C}$ for at least 24 hours. This led to a significantly improved recovery of males (Fisher 1998). 


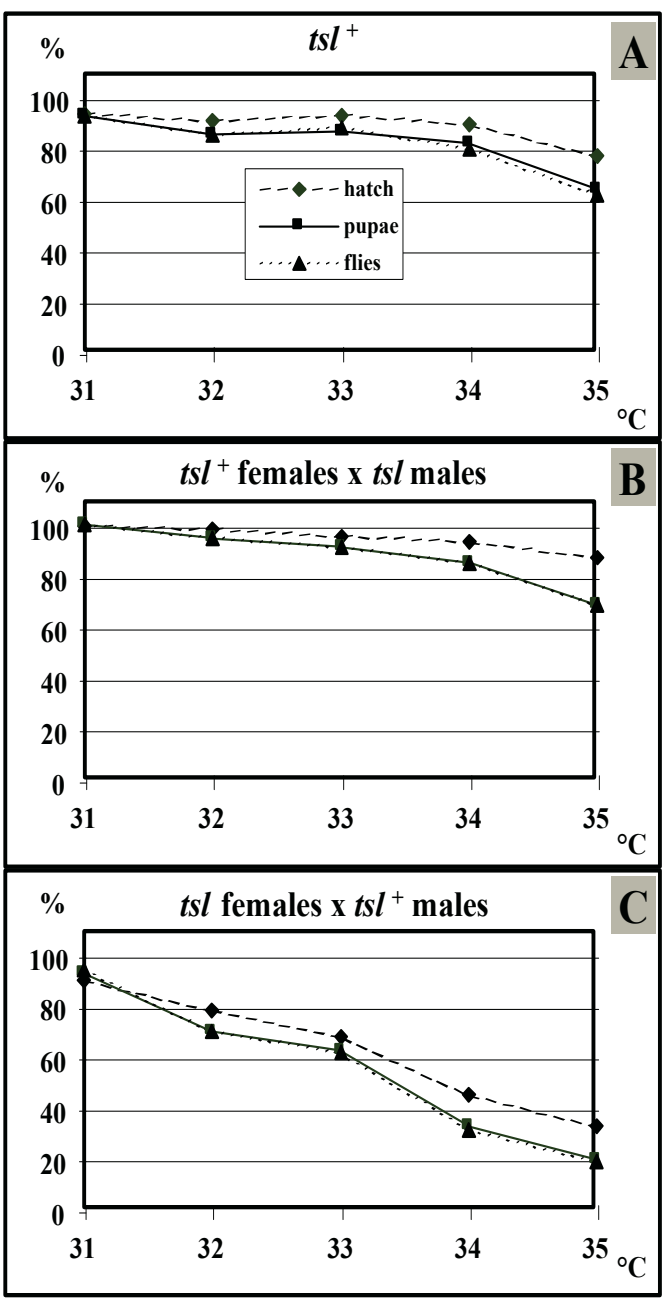

Figure 4. Difference in temperature sensitivity of $\mathrm{tsl}^{+} / \mathrm{tsl}$ genotypes depending on direction of parental cross (maternal effect). Values shown for hatch, pupae, and adults are given as percentage of values obtained at $25^{\circ} \mathrm{C}$.

Homozygous tsl strain shows no hatch starting at $34^{\circ} \mathrm{C}$. 


\subsubsection{Delayed Development}

Individuals homozygous for the $t s l$ mutation develop more slowly than those either heterozygous or homozygous for a wild-type allele. Already at $25^{\circ} \mathrm{C}$, homozygous $t s l$ individuals pupate 1 day later than the wild type. If eggs and larvae are subjected to an extended incubation at elevated but sub-lethal temperatures, e.g. $29^{\circ} \mathrm{C}$, the speed of development is affected. As expected, the development of wild-type individuals is accelerated, i.e. pupation occurs 2 days earlier than at $25^{\circ} \mathrm{C}$. However, in the homozygous $t s l$ strain, pupation occurs only 1 day earlier than at $25^{\circ} \mathrm{C}$, i.e. 2 days later than the $t s l^{+}$individuals.

Differences in pupation time are a good indicator of the temperature increase during larval rearing. For example, poor rearing conditions, like excess heat in the larval diet, become apparent as increased differences in the pupation time of $t s l^{+}$males and homozygous $t s l$ females.

In principle, the delayed development of the homozygous $t s l$ females could be used to separate the sexes at the larval or pupal stages, e.g. for mass-rearing of larval or pupal parasitoids. In mass-rearing a $t s$-based GSS, the first day of pupal collection yields virtually only male pupae, but the collection on the $5^{\text {th }}$ day contains mostly females (Fig. 5 in Caceres 2002). This permits loading production cages with an excess of females (to increase egg production) without using a mechanical pupal separator. The surplus of males can be added to the insects to be irradiated and released.

\subsubsection{Unwanted Recombinants and Filter Rearing System}

An additional improvement to maintain GSS stability or purity is the filter rearing system (FRS) (section 4.3.), i.e. the maintenance of a mother colony as a pure GSS where any exceptional flies are removed according to their pupal colour phenotype (Cáceres et al. 2000; Parker, Mamai et al., this volume). As described below, GSSs can generate unwanted recombinant individuals, some of which cannot be removed by inspection of the pupal colour (Table 2).

Table 2. Recombinant types produced in $T(Y ; 5) \mathrm{wp}^{+} \mathrm{tsl}^{+} / \mathrm{wp}$ tsl males

\begin{tabular}{|c|c|c|c|c|}
\hline $\begin{array}{l}\text { Recombination } \\
\text { type }\end{array}$ & $\mathrm{F}_{1}$ genotype & $F_{1}$ phenotype & $\begin{array}{l}\text { Accumulation } \\
\text { in mass- } \\
\text { rearing }\end{array}$ & $\begin{array}{c}\text { Detection in } \\
\text { filter rearing } \\
\text { system }\end{array}$ \\
\hline Type-1a & $\begin{array}{c}\mathrm{T}(\mathrm{Y} ; 5) w p \text { tsl/wp tsl } \\
\text { males }\end{array}$ & $\begin{array}{c}\text { white pupae, } t s l \\
50 \% \text { sterile }\end{array}$ & No & Yes \\
\hline Type-1a & $\begin{array}{c}w p^{+} t s l^{+} / w p \text { tsl } \\
\text { females }\end{array}$ & brown pupae, $t s l^{+}$ & Yes & Yes \\
\hline Type-1b & $\begin{array}{c}\mathrm{T}(\mathrm{Y} ; 5) w p^{+} t s l / w p t s l \\
\text { males }\end{array}$ & $\begin{array}{l}\text { brown pupae, } t s l \text {, } \\
50 \% \text { sterile }\end{array}$ & No & No \\
\hline Type-1b & $\begin{array}{c}w p t s l^{+} / w p \text { tsl } \\
\text { females }\end{array}$ & white pupae $t s l^{+}$ & Yes & No \\
\hline Type-2 & $\begin{array}{l}\mathrm{Y} / w p \text { tsl/wp tsl } \\
\text { males }\end{array}$ & $\begin{array}{c}\text { white pupae, } t s l, \\
100 \% \text { fertile }\end{array}$ & Yes & Yes \\
\hline
\end{tabular}


One type of recombinant female, $w p t s l^{+} / w p t s l$, emerges from white pupae, and therefore is not removed by the FRS, and will accumulate in the colony, where it becomes evident when an increasing number of white-pupae females survive the temperature treatment. However, such females can be distinguished from the nonrecombinant females since the presence of the $t s l^{+}$allele causes them to pupate early, together with the males. Consequently, it is recommended for the FRS that new adult cages be set up with only brown-pupae males that have pupated early, and with whitepupae females that have pupated late. It has been shown that this selection scheme significantly improves the accuracy of the FRS.

\subsubsection{Large-Scale Temperature Treatment of Embryos}

In mass-rearing, eliminating female embryos requires only a simple and cheap water bath. The temperature treatment is applied during the "egg bubbling stage" when incubating eggs are oxygenated and maintained at a high density in water. The accuracy of the treatment is almost $100 \%$, even in very large facilities where hundreds of millions of eggs are treated every day (Caceres 2002). Male quality and quantity is not affected significantly by the treatment. In rearing individuals for the colony, temperature must be carefully controlled; if not, female production is reduced, and, as described below, the stability of the sexing system is negatively affected (section 4).

\subsection{Sex Linkage of Selectable Marker}

Selectable markers are generally not sex-specific. Therefore, the respective wild-type allele must be linked to the male-determining $\mathrm{Y}$ chromosome. In Mediterranean fruit fly, this linkage is achieved by irradiating wild-type pupae with 40-50 Gy, and backcrossing individual $F_{1}$ males with mutant females carrying the selectable markers. The $F_{2}$ is screened for lines where the mutation used in the screen is inherited in a sexspecific manner, i.e. males are wild type and the females mutant. The choice of the mutation determines which autosome is involved in the translocation.

Several independent experiments to induce $\mathrm{Y}$-autosome translocations in the Mediterranean fruit fly have been performed (Robinson and Van Heemert 1982; Kerremans et al. 1992; Franz et al. 1994; Kerremans and Franz 1995; Delprat et al. 2002). On average, about $7 \%$ of $F_{1}$ crosses involve male-linked translocations. This frequency depends on the genome size and the size of the chromosomes involved. In total, more than $30 \mathrm{Y}$-autosome translocations involving chromosome 5 were generated. Chromosome 5 carries both the $w p$ and $t s l$ mutants. This diverse availability of translocations is a very important prerequisite for the successful development of sexing strains - it allows a choice of the most appropriate translocation (with reference to stability and productivity).

The productivity of a sexing strain is correlated primarily with the segregation behaviour of a $\mathrm{Y}$-autosome translocation during male meiosis. There are two ways in which a Y-autosome translocation can segregate - alternate and adjacent-1 (Fig. 5).

In nearly all cases, these two types occur at equal frequencies (Franz 2000; G. Franz, unpublished data). Only alternate segregation leads to genetically balanced offspring, but adjacent-1 segregation results in severe deletions and triplications. 
Deletions usually cause lethality already during embryogenesis, but triplications can survive, depending on the size and resulting sex, until the pupal or even adult stages. As a consequence of this segregation pattern, only $50 \%$ of the offspring produced by males carrying a simple translocation, involving only one autosome, are genetically balanced, i.e. males are $50 \%$ sterile. In males with a more complex translocation, where more than one autosome is involved, sperm sterility is increased accordingly (Franz 2000).

The structure of the translocation, in particular the structure of the Y chromosome and the location of the break point on the $\mathrm{Y}$ chromosome, affects the segregation behaviour and the viability of the resulting adjacent-1 offspring (Willhoeft and Franz 1996). If the break point is located between the Y-chromosomal centromere and the Maleness factor, the triplication-type adjacent-1 individuals will be female, e.g. strains VIENNA 7 and 8 (sections 4.1. and 4.2.; Robinson et al. 1999). It has been shown that females are about 100-fold more sensitive to triplications in most regions of chromosome 5 than males with triplications of similar size (G. Franz, unpublished data), and consequently they do not survive to the pupal stage. Additional rearrangements of the $\mathrm{Y}$ chromosome can lead to an increase in the alternate segregation frequency and, thereby, to an increase in the productivity of the strain.

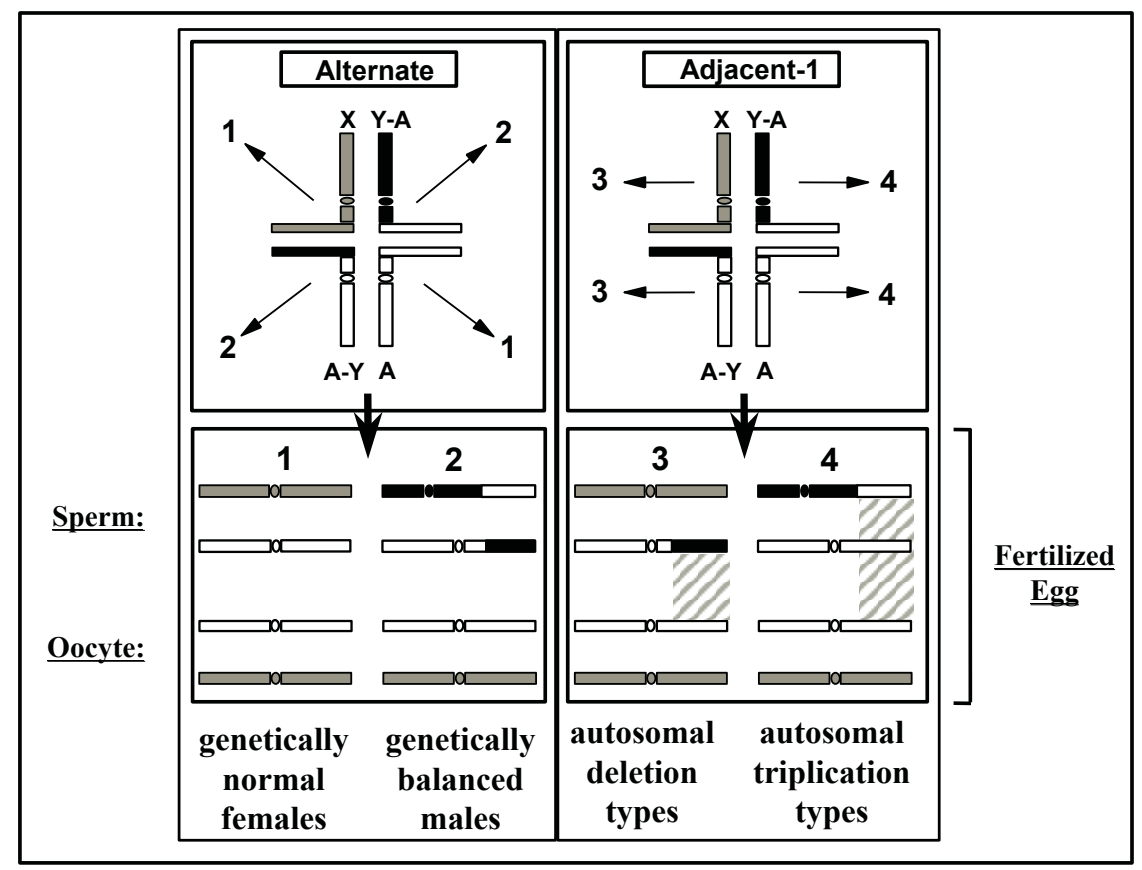

Figure 5. Two different types of segregation of Y-autosome translocations during male meiosis.

$Y$-A: translocation fragment carrying $Y$ chromosomal centromere,

$A-Y$ : reciprocal translocation fragment carrying autosomal centromere,

$X$ : X chromosome, A: autosome. Adjacent-2 segregation represents a non-disjunction of homologous centromeres, and therefore is not considered here. 


\section{INSTABILITY IN SEXING SYSTEM}

The first Mediterranean fruit fly sexing strain was based on the $w p$ mutation and the translocation T(Y;5)101 (Robinson and Van Heemert 1982). In laboratory-scale rearing, no obvious signs of instability were detected. In 1985, this strain was tested in mass-rearing. Although the scale of production was rather limited (about 1 million males per week), within a relatively short period the sexing system started to degrade (Hooper et al. 1987). The following actions were taken to remedy the situation:

- Improving cytology, and developing chromosome maps. During the development of polytene chromosome maps, it was discovered that there are two classes of tissues that contain polytene chromosomes with completely different banding patterns (Bedo 1986; Zacharopoulou 1987, 1990, 1991), and the Y chromosome is visible only in polytene chromosomes isolated from trichogen cells in male suborbital frontal bristles.

- Induction, analysis, and mapping of new mutations. Many new mutations were isolated and genetic maps constructed (Rössler et al. 1994). To date, seven phenotypic mutations are known for chromosome 5, several of which were mapped on polytene chromosomes by deletion mapping or in situ hybridization (Fig. 6).

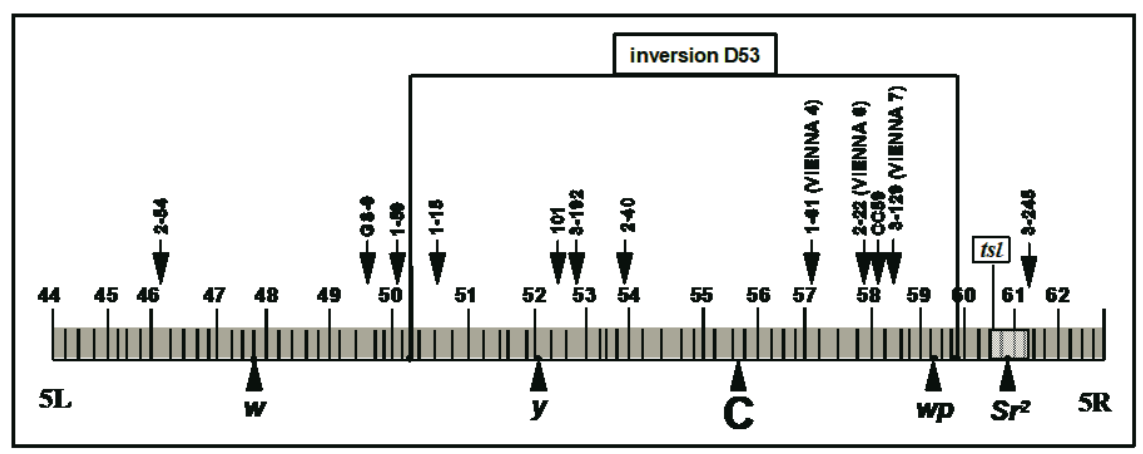

Figure 6. Schematic polytene Mediterranean fruit fly chromosome map of autosome 5 from trichogen cells: map positions of mutations white $(\mathrm{w})$, yellow body $(\mathrm{y})$ and Sergeant ${ }^{2}\left(\mathrm{Sr}^{2}\right)$ are shown in addition to location of selectable markers wp and tsl. Arrows indicate break points of several Y-autosome translocations. Extent of chromosomal region inverted in D53 is shown. C: centromere. (VIENNA 8 includes translocation 101 combined with inversion D53.)

\subsection{Type-1 Male Recombination}

The most frequent cause of strain instability is autosomal recombination in males heterozygous for the selectable marker(s), i.e. recombination between the translocated wild-type chromosome and the free autosome carrying the mutant alleles (type-1 recombination, Franz 2002). In the GSSs being used in operational programmes that apply the SIT, where $w p$ and $t s l$ are used as selectable markers, genetic recombination 
in two chromosomal regions is of relevance, i.e. in the region between the translocation break point and $w p$ (type-1a), and the region between $w p$ and $t s l$ (type1b, Fig. 7). Each sub-type produces two reciprocal recombinants; type-1a replaces the wild-type alleles of both markers on the translocation with the mutant alleles from the free autosome, while type- $1 \mathrm{~b}$ exchanges only the wild-type allele of the $t s l$. This results in the generation of several new combinations of these markers and sex (Table 2).

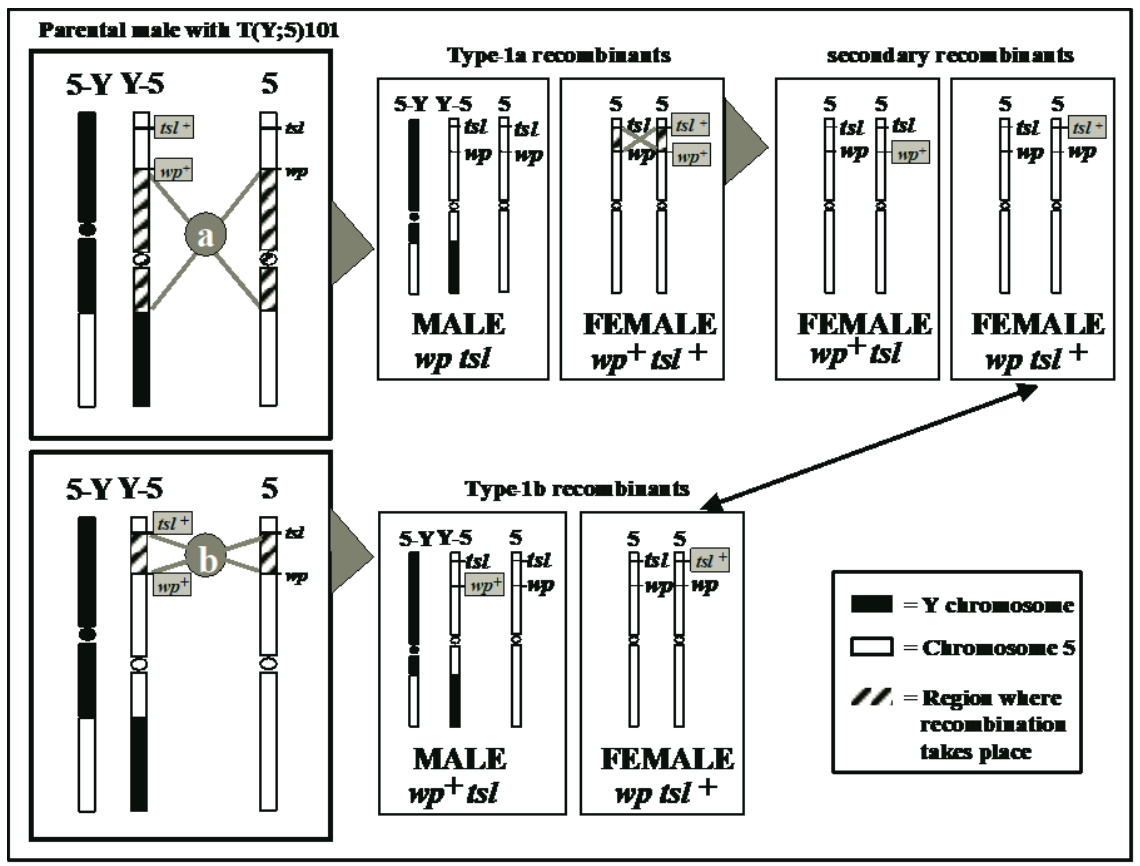

Figure 7. Consequences of type-1 recombination in Y-autosome 5 translocation $T(Y ; 5) 101$, either in chromosomal region between translocation break point and $\mathrm{wp}$ (type-1a) or between wp and tsl (type-1b). Also, the genotype resulting from secondary recombination in type-1a recombinant females is shown. 5-Y: translocation fragment carrying chromosome 5 centromere, $Y$-5: reciprocal translocation fragment carrying $Y$ chromosomal centromere.

In Mediterranean fruit fly males, the recombination frequency is very low, especially compared with recombination in females. For example, the recombination frequency between the relatively distant mutations white $(w)$, on the left arm of chromosome 5, and $w p$ on the right arm, is $0.176 \%$ in males (Franz 2002) but $48.4 \%$ in females (Rossler and Rosenthal 1992), i.e. these two markers behave as if they were unlinked in females. In spite of its rare occurrence, male recombination is nevertheless a threat to the integrity of the sexing system since some of the resulting recombinants have a selective advantage as compared with normal non-recombinant flies. In a continuous mass-rearing system, where exceptional individuals cannot be removed, 
they will gradually replace the non-recombinant genotypes. To illustrate this, a GSS, based on the translocation T(Y5)101 (Robinson and Van Heemert 1982) and the markers $w p$ and $t s l$, was reared in standard small-scale conditions for more than 3 years. In each generation, $34 \mathrm{ml}$ of pupae were taken to initiate the next generation without removing any recombinants; in parallel, flies emerging from $40 \mathrm{ml}$ of pupae were screened for recombinants (Fig. 8). A typical pattern of strain degradation due to type- 1 recombination emerges from generation 20 onwards. During male meiosis the two reciprocal types of recombinants, $w p^{+}$females and $w p$ males, occur at equal frequencies. However, from generation 20 onwards, the $w p^{+}$female recombinants accumulate rapidly, while the number of $w p$ males remains insignificant. The accumulation of $w p^{+}$females is even faster than expected based on a purely additive build-up of the recombinants occurring in each generation. This effect is caused by the selective pressure in favour of these wild-type females during the mass-rearing process.

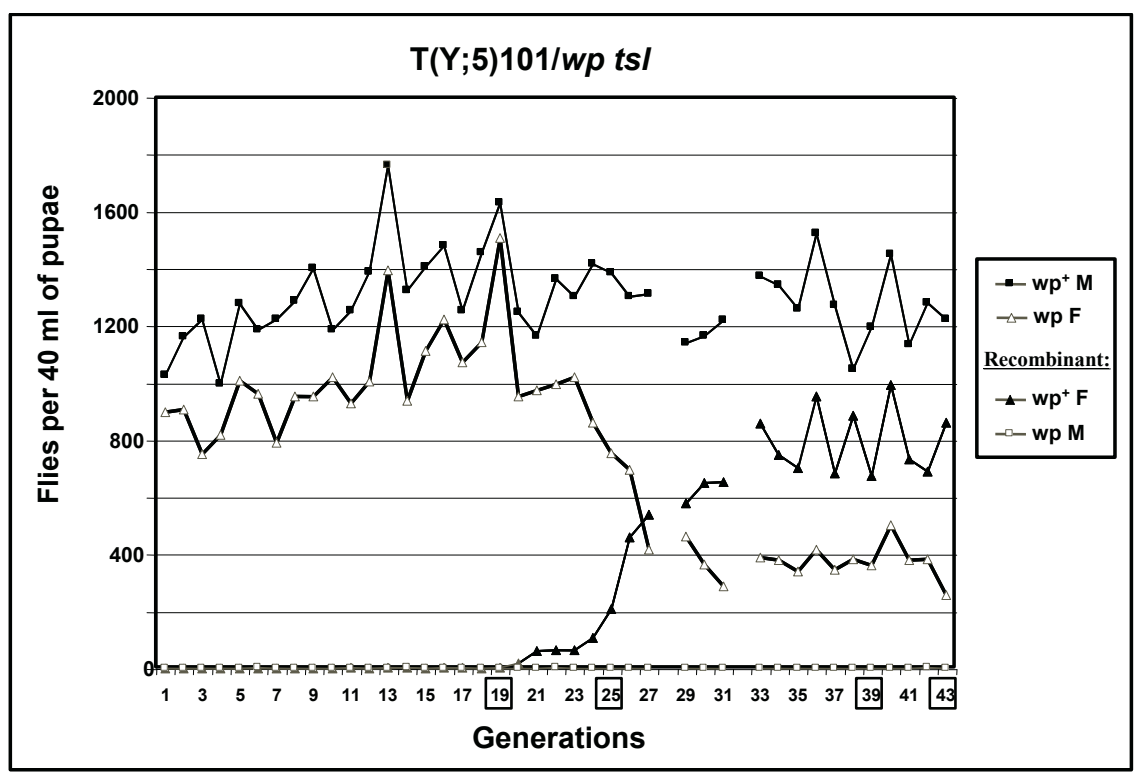

Figure 8. Breakdown pattern of genetic sexing strain T(Y;5)101/wp tsl. In each generation, $34 \mathrm{ml}$ of pupae were taken to initiate the next generation, without removing any recombinants, and a parallel sample of $40 \mathrm{ml}$ of pupae was analysed. Temperature tests were conducted with females from highlighted generations (Fig. 9). $F$ : females, M: males.

The reverse argument applies to $w p$ males; they have a selective disadvantage compared with normal non-recombinant males, and therefore do not accumulate. Furthermore, the accumulation of $w p^{+}$females continues until, in about generation 33, a certain equilibrium is reached, where these wild-type females are about twice as abundant as the non-recombinant mutant females. 
Temperature tests were needed to assess the exact nature of the recombinants, with respect to the $t s l$ mutation. In generations $19,25,39$, and 43, eggs from the colony were treated for 24 hours with temperatures between 31 and $35^{\circ} \mathrm{C}$, and the phenotype of the resulting adults was scored. Fig. 9A shows that the $w p^{+}$females are also wild type for the $t s l$ mutation (no reduction in numbers with increasing temperature), confirming that they are type-1a recombinants that resulted from recombination between the translocation break point and $w p$. As expected from the results shown in Fig. 8, such recombinants are not present in generation 19. However, in generation 25, $w p^{+} t s l^{+}$females are detected, and their frequency reaches a maximum in generations 39 and 43. Fig. 9B shows the survival of $w p$ females following temperature treatment. In generation 19, all $w p$ females are temperature sensitive, i.e. their genotype is therefore $w p t s l$. However, already in generation 25, about half of the $w p$ females have lost the $t s l$ (genotype $w p t s l^{+}$) (they survive even at $35^{\circ} \mathrm{C}$ ).

In generations 39 and 43, all $w p$ females are $t s l^{+}$. As indicated in Fig. 7, there are two ways to explain the occurrence of these $w p t s l^{+}$females, i.e. either by type- $1 \mathrm{~b}$ recombination in the males, or by a secondary recombination in the recombinant $w p$ $t s l / w p^{+} t s l^{+}$females. The latter is the most likely explanation since recombination in females is much higher than in males. Furthermore, results with other strains show that type- 1 b recombination appears to be very rare (see below).

In conclusion, type-1 recombination, in combination with a secondary recombination in females, leads to a strain where the normal $w p$ tsl females are completely replaced by a 2:1 ratio of $w p^{+} t s l^{+}$and $w p t s l^{+}$females. The rate at which these recombinant females increase in number cannot be explained by simply adding the recombinants that occur in each generation. A very strong selection is acting on the colony, leading to the rapid accumulation of recombinants that display an advantageous phenotype. The primary increase in selective advantage is caused by the loss of temperature sensitivity and, consequently, no other types of recombinants accumulate. The presence of the $w p$ mutation also causes a selective disadvantage (also noted in other combinations) (Fig. 7 in Franz 2002). The speed of accumulation will depend greatly on the rearing conditions, i.e. if they are sub-optimal, this effect will be accelerated.

An additional exceptional phenomenon can be observed only in large mass-rearing facilities. In the colony production line, pupal trays resulting from the first larval collection day, which normally consist of $w p^{+} t s l^{+}$male pupae, may also contain very few $w p$ pupae. It is known that homozygous $t s l$ individuals do not accelerate their development in response to elevated temperatures ("slow development") as a wild type strain (or a heterozygous $t s l^{+} / t s l$ individual) would. So, the earlier pupal collections in a GSS are mostly $w p^{+} t s l^{+}$males, while later pupal collections primarily consist of $w p$ tsl females. So, white pupae females detected in early pupal collections are expected to be due to recombination events between the $w p$ and $t s l$ loci. There has also been preliminary evidence that the "slow development" phenotype may not be directly associated with the $t s l$ locus itself, suggesting that this is due to a different locus, namely slow larvae $(s l)$, which should be close to the $t s l$ locus on chromosome 5 . 


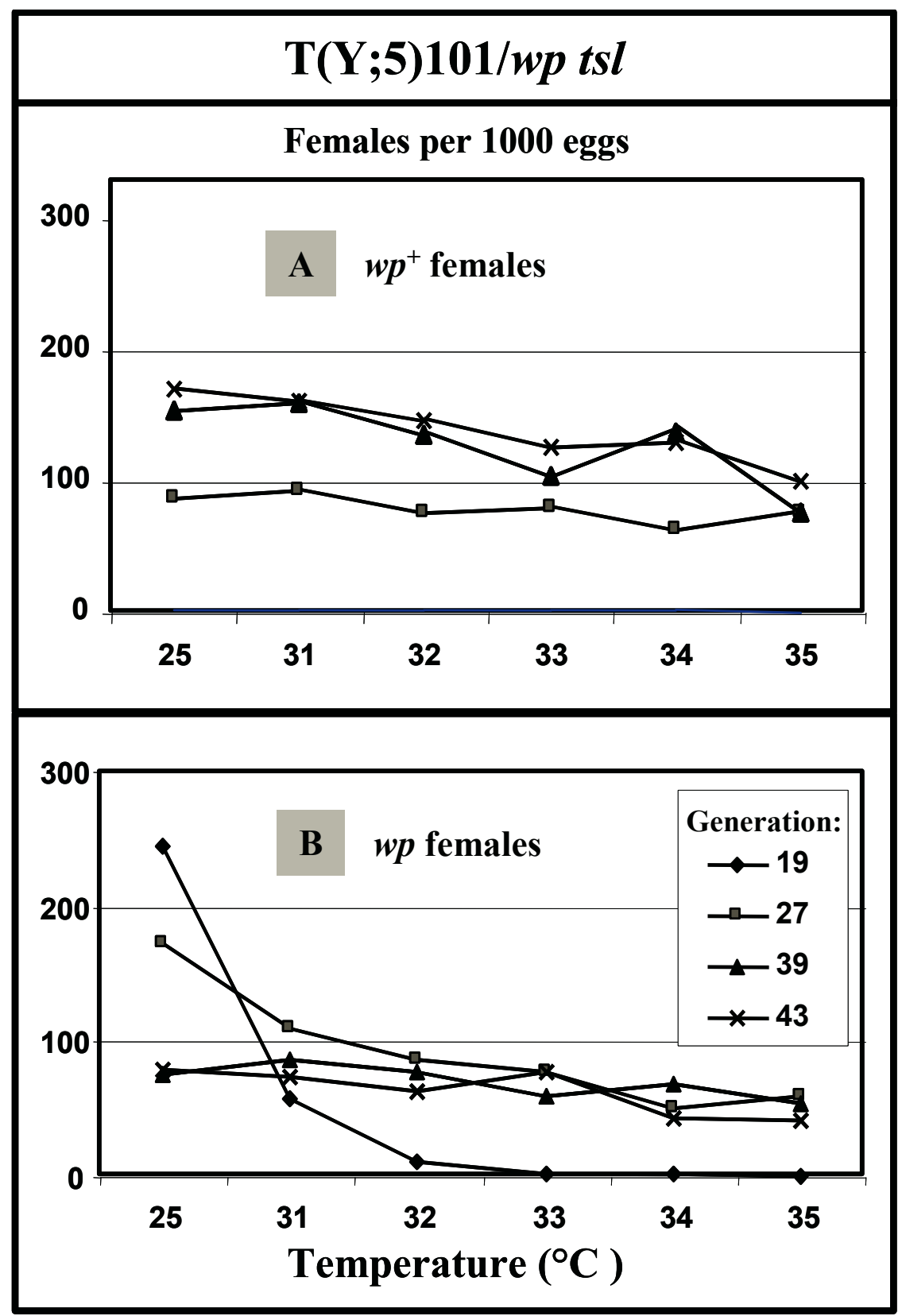

Figure 9. Temperature tests with females of sexing strain T(Y;5)101/wp tsl. Temperature tests were done in generations 19, 27, 39, and 43. 
In an effort to confirm this hypothesis, early $w p$ females were crossed with males from the balancer line $68 \mathrm{~b}$ (Gourzi et al. 2000), the $\mathrm{F}_{1} w p^{+}$progeny was inbred, and the $\mathrm{F}_{2} w p$ individuals were screened for lines homozygous for $w p t s l$ exhibiting an accelerated development. Temperature response tests confirmed that a few lines, which were homozygous for $w p$ and $t s l$, exhibited faster development during the larval stage, confirming that this phenotype is due to its close association with $w p$ and $t s l$ loci in region 61 of the polytene chromosome map (Fig. 6). After the establishment of $\mathrm{sl}^{+}$I $s l^{+}$lines, crosses were performed as described in section 2.2., which resulted in lines with $w p$ tsl female larvae that develop faster, almost like the $w p^{+} t s l^{+}$male larvae (M. Porras, personal communication). Rare recombination events, which can only be detected under mass-rearing conditions, may result in the loss of this phenotype (Type1c male recombination).

The isolation of the $s l$ locus is of major applied importance because a $w p$ tsl line in which females develop almost as fast as males would significantly increase the rearing efficiency and reduce the overall costs. This is because males and females will have access to the same amount and quality of larval food, so facilities will reduce larval rearing time, and thus space and energy consumption required for colony maintenance. In any case, protocols still need to be developed and validated for this new strain at mass-rearing facilities prior to its incorporation in large-scale operational programmes (M. Porras, personal communication). Interestingly, a similar slow larval development phenotype was described recently in A. ludens (Meza et al. 2019).

\subsection{Type-2 Male Recombination}

During mass-rearing, a second type of male recombination was detected (G. Franz, unpublished data). It is very rare (estimated frequency about $10^{-5}$ or less), and generates males with free untranslocated $\mathrm{Y}$ chromosomes that are homozygous for $w p$ and $t s l$ (Table 2). Such males accumulate rapidly in the mass-rearing colony (even though they are sensitive to temperature) because they are completely fertile. Their primary effect is on the productivity of the colony, and not on the accuracy of sexing, because together with females they are eliminated during the temperature treatment. The current hypothesis is that recombination occurs between the two translocated $\mathrm{Y}$ fragments. Choosing the appropriate $\mathrm{Y}$-autosome translocation, e.g. where the $\mathrm{Y}$ chromosomal break point is close to the centromere, can minimize this problem.

\section{STRATEGIES TO IMPROVE STABILITY}

Genetic tools are required to improve the stability of sexing strains, and two types of positional information are absolutely essential: (1) the position of the translocation break point, and (2) the position of the selectable marker(s). Also, at least one mutation per chromosome is needed to determine the structure (e.g. which autosomes are involved) and the genetic behaviour of the translocations.

There are two principal strategies to increase the stability of sexing strains. Firstly, by selecting translocations where the break point and the marker are close together, type-1 recombination can be reduced. Secondly, by incorporating inversions that cover 
the critical region between the translocation break point and the selectable marker into the strain to eliminate, or at least reduce, type-1 recombination.

\subsection{Improved Y-Autosome Translocations}

The $w p$ mutation is at position $59 \mathrm{~B}$ on the trichogen polytene map, and the $t s l$ is located in the interval 60B-61B (Fig. 6) (Kerremans and Franz 1994; G. Franz, unpublished data). More than 30 translocations were analysed to determine: (1) the position of the break point on chromosome 5 (Kerremans et al. 1990; Franz et al. 1994; Kerremans and Franz 1995), (2) the position of the break point on the Y chromosome (Willhoeft and Franz 1996), and (3) the genetic behaviour (e.g. sterility and segregation behaviour). Based on this information, three strains were selected, i.e. T(Y;5)1-61 (VIENNA 4), T(Y;5)2-22 (VIENNA 6), and T(Y;5)3-129 (VIENNA 7). They were subjected to extensive stability tests, following the same protocol as described above for strain T(Y;5)101 (Franz 2002).

After small-scale rearing for up to 95 generations, no recombinants accumulated in the strains. The overall frequency of type-1a recombination was between 0.017 and $0.021 \%$, and that of strain $\mathrm{T}(\mathrm{Y} ; 5) 101$ was $0.084 \%$ (if only the generations before recombinants started accumulating were considered). Furthermore, no obvious decrease in sensitivity was shown by the temperature tests, indicating that here also type- $1 \mathrm{~b}$ recombination did not occur at any significant level. Since the distance between the $w p$ and $t s l$ in the three new strains is the same as in $\mathrm{T}(\mathrm{Y} ; 5) 101$, the absence of $w p t s l^{+}$individuals support the hypothesis that the occurrence of such genotypes during the rearing of $\mathrm{T}(\mathrm{Y} ; 5) 101$ was caused by a secondary recombination event in the $w p t s l / w p^{+} t s l^{+}$recombinant females.

\subsection{Inversions}

The second strategy is to use the known recombination-reducing properties of chromosomal inversions. Chromosomal inversions render recombinants non-viable if the recombination has occurred within the inversion. Therefore, the aim was to induce an inversion in the wp tsl chromosome. Ideally, it should cover the interval between the translocation break point and the $t s l$ mutation, and it must be viable in a homozygous condition. The genotype of the resulting strain would be $\mathrm{T}(\mathrm{Y} ; 5)$ $w p^{+} t s l^{+} /$Inv $w p$ tsl males $\mathrm{x}$ Inv $w p t s l /$ Inv $w p$ tsl females.

In a large screen for inversions, using reduced recombination in the interval between the mutation yellow body $(y)$ and $w p$ as indicator, one homozygous viable inversion, D53 (wp tsl), was detected (A. Zacharopoulou, C. Cáceres, and G. Franz, unpublished data). Unfortunately, it does not cover the $t s l$, i.e. it would not reduce type-1b recombination. However, recombination tests with $w p$ and the mutation Sergeant ${ }^{2}\left(S^{2}\right)$, located very close to $t s l$ (Fig. 6) (Niyazi et al. 2005), showed that inversion D53 also has a strong recombination-reducing effect in neighbouring areas (G. Franz, unpublished data).

Based on this finding, D53 was combined experimentally with the translocation $\mathrm{T}(\mathrm{Y} ; 5) 101$, and a new strain VIENNA 8 was constructed. This strain was reared for 5 years (60 generations), under the same conditions as $\mathrm{T}(\mathrm{Y} ; 5) 101$, without inversion. 
When the results in Fig. 10 are compared with those in Fig. 8, it is apparent that stability is improved significantly, i.e. no $w p^{+}$females (type-1a) were detected. Temperature tests with $w p$ females showed also that no $w p t s l^{+}$female recombinants (type-1b) accumulated in the colony (Fig. 11), even though the inversion covers only a small proportion of the $w p$-tsl interval.

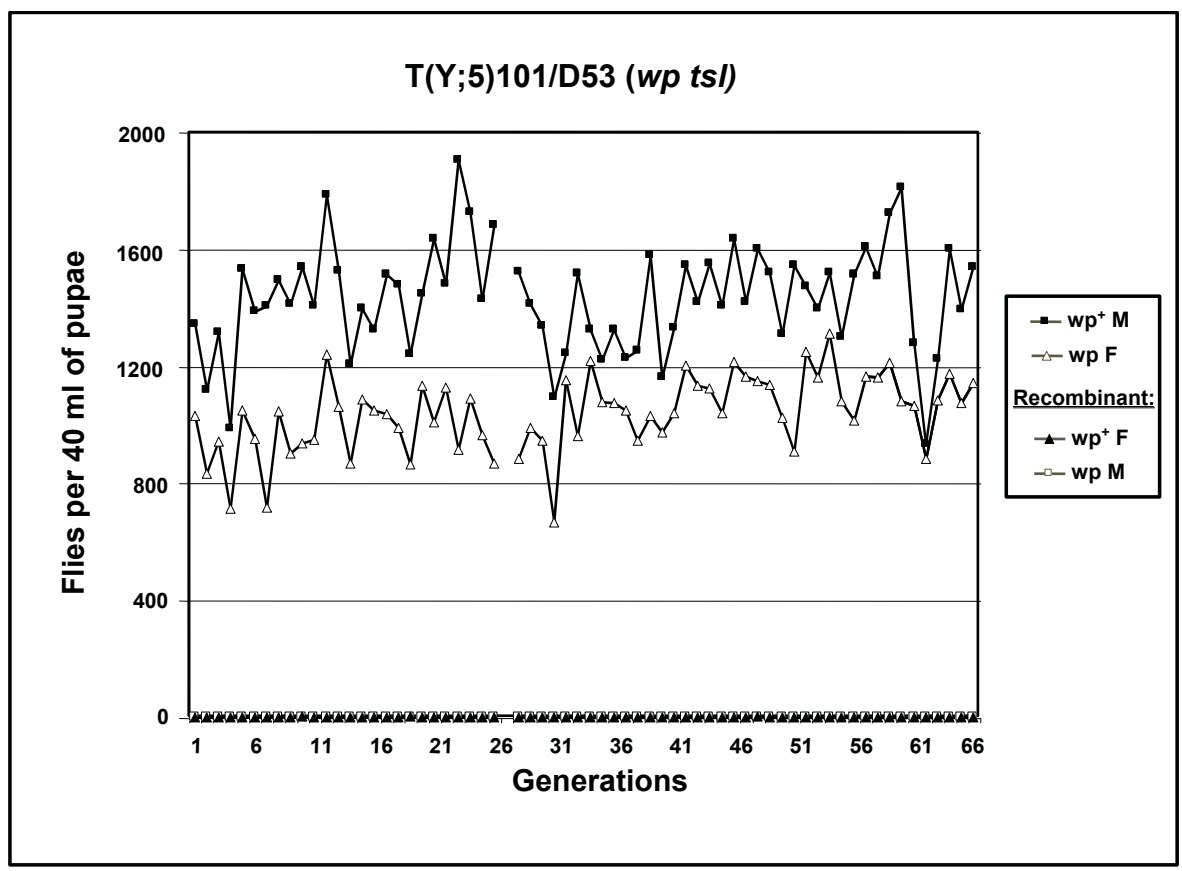

Figure 10. Increased strain stability due to presence of inversion D53. Neither $\mathrm{wp}^{+}$females nor wp males are detected at significant levels. Rearing and analysis were identical to the experiment without inversion. In several generations, wp females were tested for temperature sensitivity (Fig. 11). F: females, M: males.

Both genetic strategies to improve the stability of sexing strains have been successful. Using the appropriate translocation reduces the recombination frequency by 0.65 , and if an inversion is added, the frequency is reduced by another 0.80 . Inversions have the added potential that they permit translocations based on criteria other than stability to be used. For example, translocation $\mathrm{T}(\mathrm{Y} ; 5) 101$ causes less sterility (10-30\%, G. Franz, unpublished data) than other translocations, but is not very stable. However, in combination with inversion D53 in strain VIENNA 8, stability is very high. VIENNA 8 has now been provided to several operational AWIPM programmes that integrate the SIT (Augustinos et al. 2017). 


\section{$\mathrm{T}(\mathrm{Y} ; 5) 101 / \mathrm{D53}$ (wp tsl)}

\section{Females per 1000 eggs}

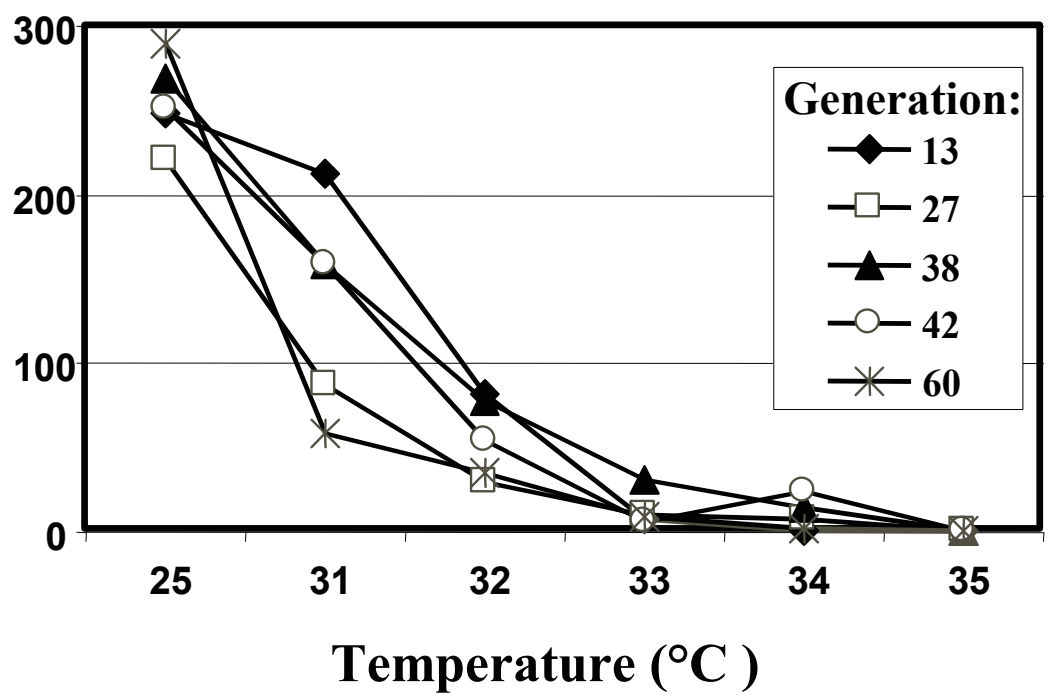

Figure 11. Temperature tests with wp females from five different generations during rearing of sexing strain $T(Y ; 5) 101 / D 53$.

\subsection{Filter Rearing System (FRS)}

Nevertheless, no GSS will be absolutely stable under conditions of large-scale massrearing. Experience with GSSs in different mass-rearing facilities has shown that rearing conditions and the scale of mass-rearing determine whether or not the stability of a strain can be maintained. Up to a certain level of mass-rearing, a facility with well-trained personnel, appropriate equipment, and adjusted operating procedures can maintain the stability. However, if the level of mass-rearing is very high, or any of the aforementioned requirements are not met, stability cannot be guaranteed, and additional measures are required (Caceres et al. 1993). It is for this purpose that the FRS was developed to help maintain the purity of the mother colony (Cáceres et al. 2000; Fisher and Caceres 2000; Parker, Mamai et al., this volume). In a systems approach, by avoiding the accumulation of recombinants, the FRS provides a second independent procedure to maintain strain integrity. Only with both strategies in place (genetically improved strains and improved mass-rearing procedures that also include a FRS) is it possible to produce more than 3500 million Mediterranean fruit fly males per week (Table 1). However, it must be emphasized that the FRS can be used only when a visible mutation is included in the GSS. 


\section{ADDITIONAL FEATURES: MARKERS}

GSSs should carry markers (internal as well as external) that make them distinguishable from wild flies or other strains. Markers make it possible to: (1) detect the deliberate or accidental contamination of a strain with wild flies or flies from a different strain, (2) determine if non-irradiated flies (especially females) were released, and (3) reduce the biological and economic costs of, and ambiguities in, the currently used procedure for marking released flies (adults emerge from pupae coated with powdered fluorescent dye) (Dowell et al., this volume; Parker, Mamai et al., this volume; Vreysen, this volume).

To achieve this goal in the Mediterranean fruit fly, several strategies have been pursued. First, a particular type of mitochondrial DNA (mtDNA) haplotype was introduced into the GSS. This mtDNA haplotype was detected in a wild-type strain from Egypt, and it can be used to differentiate the GSS from most field populations where AW-IPM programmes integrating the SIT are being carried out. The mitochondrial genome of the Mediterranean fruit fly has been fully sequenced (Spanos et al. 2000). It was used for the development of a molecular approach to assess the mating success of sterile Mediterranean fruit fly VIENNA 8 males in SIT programmes (San Andrés et al. 2007; Juan-Blasco et al. 2013). In addition, microsatellite markers have been developed which have been used for genotyping purposes (Bonizzoni et al. 2000, 2001, 2004; Stratikopoulos et al. 2008; Karsten et al. 2013; Todd et al. 2017). The genome of the Mediterranean fruit fly has recently been sequenced, thus providing a wealth of information which can be exploited for the development of novel, faster, and more accurate genotyping (Papanicolaou et al. 2016). An alternative approach was based on the introduction of the dominant mutation $S^{2}$ (Niyazi et al. 2005) into GSSs, with males distinguishable from wild males because they show three instead of two white stripes on the abdomen.

\section{FUTURE PERSPECTIVES}

Currently, the wp tsl-based Mediterranean fruit fly and the $b p$-based Mexican fruit fly GSSs are used worldwide. The capacity to produce sterile males of the Mediterranean and Mexican fruit flies using these GSSs is expected to increase steadily. In many existing facilities, production will increase, and several new facilities are being constructed or expanded, e.g. Mexico, Morocco, and USA (Mission, Texas). Several countries want to use the technology for pest suppression to decrease the reliance on insecticides. The Mediterranean and Latin-American regions may eventually represent a market of 4000 million sterile Mediterranean fruit fly males per week.

Beyond the Mediterranean and Mexican fruit flies, there is an increasing need to develop GSSs for other insect species of agricultural or public health importance, particularly in the case of mosquitoes where the females are the disease vectors, and thus the removal of the females prior to the release of sterile males is mandatory (Marec et al. 2005; Bourtzis et al. 2016; Hendrichs and Robinson, this volume). Since the genetics of many pest species is not well known, using Mendelian genetics to develop a GSS takes some time. Part of the reason for this long lead time is that Mendelian genetics involves several unknowns. For example: 
- Inducing desirable mutations, like the $t s l$ mutation in the Mediterranean fruit fly, in other species is a very unpredictable process, with no guarantee that such selective markers will be identified. Genetic markers, potentially useful for sex separation at the pupal stage, are relatively easy to isolate. Therefore, they should be exploited until an efficient and robust embryonic female killing system is developed.

- Translocation induction is also a random process, and based on experiences with the Mediterranean fruit fly, there are at least two criteria that have to be used to select useful translocations: (1) only one autosome should be involved, and (2) the positions of the break points on the autosome and the $\mathrm{Y}$ chromosome have to be known.

- Inversions will be very important in any GSS based on classical genetics, but they can also be used to facilitate screening for mutations like the $t s l$ and for outcrossing of GSSs. Screening for homozygous viable inversions is very time-consuming and labour-intensive, and requires appropriate mutations and a well-developed cytology.

In contrast to classical genetics, molecular strategies may offer the possibility of developing generic "sexing cassettes" in one species that can be transferred with only minor modifications to other closely related species (Robinson and Franz 2000; Robinson et al. 2004), using non-transgenic or transgenic approaches; this is discussed in more detail in another chapter (Häcker et al., this volume).

\section{REFERENCES}

Augustinos, A. A., A. Targovska, E. Cancio-Martinez, E. Schorn, G. Franz, C. Cáceres, A. Zacharopoulou, and K. Bourtzis. 2017. Ceratitis capitata genetic sexing strains: laboratory evaluation of strains from mass-rearing facilities worldwide. Entomologia Experimentalis et Applicata 164 (Special Issue): 305-317. https://doi.org/10.1111/eea.12612

Bailey, D. L., R. E. Lowe, D. A. Dame, and J. A. Seawright. 1980. Mass rearing the genetically altered MACHO strain of Anopheles albimanus Wiedemann. American Journal of Tropical Medicine and Hygiene 29: 141-149. https://www.ncbi.nlm.nih.gov/pubmed/7352622

Barclay, H. J., and J. Hendrichs. 2014. Models for assessing the male annihilation of Bactrocera spp. with methyl eugenol baits. Annals of the Entomological Society of America 107: 81-96. https://doi.org/10.1603/AN13046

Bedo, D. G. 1986. Polytene and mitotic chromosome analysis in Ceratitis capitata (Diptera: Tephritidae). Canadian Journal of Genetics and Cytology 28: 180-188.

Bonizzoni, M., A. R. Malacrida, C. R. Guglielmino, L. M. Gomulski, G. Gasperi, and L. Zheng. 2000. Microsatellite polymorphism in the Mediterranean fruit fly, Ceratitis capitata. Insect Molecular Biology 9: 251-261. https://doi.org/10.1046/j.1365-2583.2000.00184.x

Bonizzoni, M., L. Zheng, C. R. Guglielmino, D. S. Haymer, G. Gasperi, L. M. Gomulski, and A. R. Malacrida. 2001. Microsatellite analysis of medfly bioinfestations in California. Molecular Ecology 10: 2515-2524. https://doi.org/10.1046/j.0962-1083.2001.01376.x

Bonizzoni, M., C. R. Guglielmino, C. J. Smallridge, M. Gomulski, A. R. Malacrida, and G. Gasperi. 2004. On the origins of medfly invasion and expansion in Australia. Molecular Ecology 13: 38453855. https://doi.org/10.1111/j.1365-294X.2004.02371.x

Bourtzis, K., R. S. Lees, J. Hendrichs, and M. J. B. Vreysen. 2016. More than one rabbit out of the hat: radiation, transgenic and symbiont-based approaches for sustainable management of mosquito and tsetse fly populations. Acta Tropica 157: 115-130.

https://doi.org/10.1016/j.actatropica.2016.01.009 
Caceres, C. 2002. Mass rearing of temperature sensitive genetic sexing strains in the Mediterranean fruit fly (Ceratitis capitata). Genetica 116: 107-116. https://link.springer.com/article/10.1023/A\%3A1020967810703

Caceres, C., J. Walder, and S. Venicio. 1993. Genetic method for separation of males and females of the Mediterranean fruit fly Ceratitis capitata, based on pupal color dimorphism for mass-rearing applications, pp. 81- 84. In M. Aluja and P. Liedo (eds.), Fruit flies: biology and management. 3rd International Symposium on Fruit Flies of Economic Importance, 14-20 October 1990, Antigua Guatemala, Guatemala. Springer-Verlag, New York, USA. https://link.springer.com/chapter/10.1007/978-1-4757-2278-9_17

Cáceres, C., K. Fisher, and P. Rendón. 2000. Mass rearing of the medfly temperature sensitive lethal genetic sexing strain in Guatemala, pp. 551-558. In K. H. Tan (ed.), Proceedings: Area-Wide Control of Fruit Flies and Other Insect Pests. International Conference on Area-Wide Control of Insect Pests, and the $5^{\text {th }}$ International Symposium on Fruit Flies of Economic Importance, 28 May-5 June 1998, Penang, Malaysia. Penerbit Universiti Sains Malaysia, Pulau Pinang, Malaysia. http://www-naweb.iaea.org/nafa/ipc/public/Area-wide-control 491-650.pdf

Caceres, C., J. P. Cayol, W. Enkerlin, G. Franz, J. Hendrichs, and A. S. Robinson. 2004. Comparison of Mediterranean fruit fly (Ceratitis capitata) (Tephritidae) bisexual and genetic sexing strains: development, evaluation and economics, pp. 367-381. In B. N. Barnes (ed.), Proceedings, Symposium: $6^{\text {th }}$ International Symposium on Fruit Flies of Economic Importance, 6-10 May 2002, Stellenbosch, South Africa. Isteg Scientific Publications, Irene, South Africa. https://nucleus.iaea.org/sites/naipc/twd/Documents/6thISFFEI_Proceedings/6th-ISFFEI-Proceedings2004-Stellenbosch-South-Africa.pdf

Dame, D. A., C. S. Lofgren, H. R. Ford, M. D. Boston, K. F. Baldwin, and G. M. Jeffery. 1974. Release of chemosterilized males for the control of Anopheles albimanus in El Salvador. II. Methods of rearing, sterilization, and distribution. American Journal of Tropical Medicine and Hygiene 23: 282287. https://doi.org/10.4269/ajtmh.1974.23.282

Delprat, M. A., C. E. Stolar, F. C. Manso, and J. L. Cladera. 2002. Genetic stability of sexing strains based on the locus $s w$ of Ceratitis capitata. Genetica 116: 85-95. https://link.springer.com/article/10.1023/A\%3A1020963709795

Dowell, F. E., A. G. Parker, M. Q. Benedict, A. S. Robinson, A. B. Broce, and R. A. Wirtz. 2005. Sex separation of tsetse fly pupae using near-infrared spectroscopy. Bulletin of Entomological Research 95: 249-257. https://www.ncbi.nlm.nih.gov/pubmed/15960879/

Epsky, N. D., J. Hendrichs, B. I. Katsoyannos, L. A. Vasquez, J. P. Ros, A. Zumreoglu, R. Pereira, A. Bakri, S. I. Seewooruthun, and R. R. Heath. 1999. Field evaluation of female targeted trapping systems for Ceratitis capitata (Diptera: Tephritidae) in seven countries. Journal of Economic Entomology 92: 156-164. https://doi.org/10.1093/jee/92.1.156

(FAO/IAEA DIR-SIT) Food and Agriculture Organization of the United Nations/International Atomic Energy Agency World-Wide Directory of Sterile Insect Technique Facilities. 2020. https://nucleus.iaea.org/sites/naipc/dirsit/SitePages/All\%20Facilities.aspx

Fisher, K. 1998. Genetic sexing strains of Mediterranean fruit fly (Diptera: Tephritidae): optimizing high temperature treatment of mass-reared temperature-sensitive lethal strains. Journal of Economic Entomology 91: 1406-1414. https://doi.org/10.1093/jee/91.6.1406

Fisher, K., and C. Caceres. 2000. A filter rearing system for mass reared genetic sexing strains of Mediterranean fruit fly (Diptera: Tephritidae), pp. 543-550. In K. H. Tan (ed.), Proceedings: Area-Wide Control of Fruit Flies and Other Insect Pests. International Conference on Area-Wide Control of Insect Pests, and the $5^{\text {th }}$ International Symposium on Fruit Flies of Economic Importance, 28 May-5 June 1998, Penang, Malaysia. Penerbit Universiti Sains Malaysia, Pulau Pinang, Malaysia. http://www-naweb.iaea.org/nafa/ipc/public/Area-wide-control_491-650.pdf

Franz, G. 2000. The "Combi Fly Concept" revisited: how much radiation is required to sterilise males of a genetic sexing strain? pp. 511-516. In K. H. Tan (ed.), Proceedings: Area-Wide Control of Fruit Flies and Other Insect Pests. International Conference on Area-Wide Control of Insect Pests, and the $5^{\text {th }}$ International Symposium on Fruit Flies of Economic Importance, 28 May-5 June 1998, Penang, Malaysia. Penerbit Universiti Sains Malaysia, Pulau Pinang, Malaysia. http://www-naweb.iaea.org/nafa/ipc/public/Area-wide-control_491-650.pdf

Franz, G. 2002. Recombination between homologous autosomes in medfly (Ceratitis capitata) males: type- 1 recombination and the implications for the stability of genetic sexing strains. Genetica 116: $73-$ 84. https://link.springer.com/article/10.1023/A\%3A1020911725724 
Franz, G., and P. Kerremans. 1994. Requirements and strategies for the development of genetic sex separation systems with special reference to the Mediterranean fruit fly Ceratitis capitata, pp. 113-122. In C. O. Calkins, W. Klassen and P. Liedo (eds.), Fruit flies and the sterile insect technique. CRC Press, Boca Raton, FL, USA.

Franz, G., E. Gencheva, and P. Kerremans. 1994. Improved stability of genetic sex-separation strains for the Mediterranean fruit fly, Ceratitis capitata. Genome 37: 72-82. https://doi.org/10.1139/g94-009

Gourzi, P., D. Gubb, Y. Livadaras, C. Caceres, G. Franz, C. Savakis, and A. Zacharopoulou. 2000. The construction of the first balancer chromosome for the Mediterranean fruit fly, Ceratitis capitata. Journal of Molecular and General Genetics 264: 127-136.

https://www.researchgate.net/publication/12306585_The_construction_of_the_first_balancer_chromoso me_for_the_Mediterranean_fruit_fly_Ceratitis_capitata

Hendrichs, J., G. Franz, and P. Rendon. 1995. Increased effectiveness and applicability of the sterile insect technique through male-only releases for control of Mediterranean fruit flies during fruiting seasons. J. Applied Entomology 119: 371-377. https://doi.org/10.1111/j.1439-0418.1995.tb01303.x

Hooper, G. H. S., A. S. Robinson, and R. P. Marchand. 1987. Behaviour of a genetic sexing strain of Mediterranean fruit fly, Ceratitis capitata, during large scale rearing, pp. 349-362. In A. P. Economopoulos (ed.), Proceedings, Symposium: Fruit Flies. $2^{\text {nd }}$ International Symposium, 16-21 September 1986, Crete, Greece. Printer: G. Tsiveriotis Ltd., Athens, Greece. Distributor: Elsevier Science Publishers, Amsterdam, The Netherlands. http://www-naweb.iaea.org/nafa/ipc/public/FF-Proc-Intl-Symp-145-379.pdf

(IAEA) International Atomic Energy Agency. 2008. Model business plan for a sterile insect production facility. http://www-naweb.iaea.org/nafa/ipc/public/IAEA-MBP_SP_facility.pdf

Juan-Blasco, M., A. Urbaneja, V. San Andrés, P. Castañera, and B. Sabater-Muñoz. 2013. Improving the sterile sperm identification method for its implementation in the area-wide sterile insect technique program against Ceratitis capitata (Diptera: Tephritidae) in Spain. Journal of Economic Entomology 106: 2541-2547. https://doi.org/10.1603/EC13064

Karsten, M., B. J. van Vuuren, A. Barnaud, and J. S. Terblanche. 2013. Population genetics of Ceratitis capitata in South Africa: implications for dispersal and pest management. PLOS One 8(1): e54281. https://doi.org/10.1371/journal.pone.0054281

Kerremans, P., and G. Franz. 1994. Cytogenetic analysis of chromosome 5 from Mediterranean fruit fly, Ceratitis capitata. Chromosoma 103: 142-146. https://doi.org/10.1007/BF00352323

Kerremans, P., and G. Franz. 1995. Isolation and cytogenetic analyses of genetic sexing strains for the medfly, Ceratitis capitata. Theoretical and Applied Genetics 91: 255-261. https://doi.org/10.1007/BF00220886

Kerremans, P., K. Bourtzis, and A. Zacharopoulou. 1990. Cytogenetic analysis of three genetic sexing strains of Ceratitis capitata. Theoretical and Applied Genetics 80: 177-182. https://doi.org/10.1007/BF00224383

Kerremans, P., E. Gencheva, and G. Franz. 1992. Genetic and cytogenetic analysis of Y-autosome translocations in the Mediterranean fruit fly, Ceratitis capitata. Genome 35(2): 264-272. https://doi.org/10.1139/g92-041

Knipling, E. F. 1959. Sterile-male method of population control. Science 130(3380): 902-904. DOI: $10.1126 /$ science.130.3380.902 http://science.sciencemag.org/content/130/3380/902

Koyama, J., T. Teruya, and K. Tanaka. 1984. Eradication of the oriental fruit fly (Diptera: Tephritidae) from the Okinawa Islands by a male annihilation method. Journal of Economic Entomology 77: 468472. https://doi.org/10.1093/jee/77.2.468

Marec, F., L. G. Neven, A. S. Robinson, M. Vreysen, M. R. Goldsmith, J. Nagaraju, and G. Franz. 2005. Development of genetic sexing strains in Lepidoptera: from traditional to transgenic approaches. Journal of Economic Entomology 98: 248-259. https://doi.org/10.1093/jee/98.2.248

McCombs, S. D., and S. H. Saul. 1995. Translocation-based genetic sexing system for the oriental fruit fly (Diptera: Tephritidae) based on pupal color dimorphism. Annals of the Entomological Society of America 88: 695-698. https://doi.org/10.1093/aesa/88.5.695

McInnis, D. O., S. Tam, C. Grace, and D. Miyashita. 1994. Population suppression and sterility rates induced by variable sex ratio, sterile insect releases of Ceratitis capitata (Diptera: Tephritidae). Annals of the Entomological Society of America 87: 231-240.

https://doi.org/10.1093/aesa/87.2.231 
McInnis, D. O., S. Tam, R. Lim, J. Komatsu, R. Kurashima, and C. Albrecht. 2004. Development of a pupal color-based genetic sexing strain of the melon fly, Bactrocera cucurbitae (Coquillett) (Diptera: Tephritidae). Annals of the Entomological Society of America 97: 1026-1033. https://doi.org/10.1603/0013-8746(2004)097[1026:DOAPCG]2.0.CO;2

Meats, A., P. Maheswaran, M. Frommer, and J. Sved. 2002. Towards a male-only release system for SIT with the Queensland fruit fly, Bactrocera tryoni, using a genetic sexing strain with a temperaturesensitive lethal mutation. Genetica 116: 97-106. https://link.springer.com/article/10.1023/A\%3A1020915826633

Meza, J. S., C. Cáceres, and K. Bourtzis. 2019. Slow larvae mutant and its potential to improve the pupal color-based genetic sexing system in Mexican fruit fly, (Diptera: Tephritidae). Journal of Economic Entomology 112: 1604-1610. https://doi.org/10.1093/jee/toz094

Nagaraju, J. 2002. Application of genetic principles for improving silk production. Current Science 83: 409-414. http://repository.ias.ac.in/76683/1/76683.pdf

Niyazi, N., C. Caceres, A. Delprat, V. Wornoayporn, E. Ramirez Santos, G. Franz, and A. S. Robinson. 2005. Genetics and mating competitiveness of Ceratitis capitata (Diptera: Tephritidae) strains carrying the marker Sergeant, $\mathrm{Sr}^{2}$. Annals of the Entomological Society of America 98: 119125. https://doi.org/10.1603/0013-8746(2005)098[0119:GAMCOC]2.0.CO;2

Opiyo, E., D. Luger, and A. S. Robinson. 2000. New systems for the large-scale production of male tsetse flies (Diptera: Glossinidae), pp. 337-344. In K. H. Tan (ed.), Proceedings: Area-Wide Control of Fruit Flies and Other Insect Pests. International Conference on Area-Wide Control of Insect Pests, and the 5 th International Symposium on Fruit Flies of Economic Importance, 28 May-5 June 1998, Penang, Malaysia. Penerbit Universiti Sains Malaysia, Pulau Pinang, Malaysia. http://www-naweb.iaea.org/nafa/ipc/public/Area-wide-control_230-350.pdf

Orozco, D., J. Salvador Meza, S. Zepeda, E. Solis, and J. L. Quintero-Fong. 2013. Tapachula-7, a new genetic sexing strain of the Mexican fruit fly (Diptera: Tephritidae): Sexual compatibility and competitiveness. Journal of Economic Entomology 106: 735-741. https://doi.org/10.1603/EC12441

Papanicolaou, A., M. F. Schetelig, P. Arensburger, P. W. Atkinson, J. B. Benoit, K. Bourtzis, P. Castañera, J. P. Cavanaugh, H. Chao, C. Childers, I. Curril, H. Dinh, H. Doddapaneni, A. Dolan, S. Dugan, M. Friedrich, G. Gasperi, S. Geib, G. Georgakilas, R. A. Gibbs, S. D. Giers, L. M. Gomulski, M. González-Guzmán, A. Guillem-Amat, Y. Han, A. G. Hatzigeorgiou, P. HernándezCrespo, D. S. T. Hughes, J. W. Jones, D. Karagkouni, P. Koskinioti, S. L. Lee, A. R. Malacrida, M. Manni, K. Mathiopoulos, A. Meccariello, S. C. Murali, T. D. Murphy, D. M. Muzny, G. Oberhofer, F. Ortego, M. D. Paraskevopoulou, M. Poelchau, J. Qu, M. Reczko, H. M. Robertson, A. J. Rosendale, A. E .Rosselot, G. Saccone, M. Salvemini, G. Savini, P. Schreiner, F. Scolari, P. Siciliano, S. B. Sim, G. Tsiamis, E. Ureña, I. S. Vlachos, J. H. Werren, E. A. Wimmer, K. C. Worley, A. Zacharopoulou, S. Richards, and A. M. Handler. 2016. The whole genome sequence of the Mediterranean fruit fly, Ceratitis capitata (Wiedemann), reveals insights into the biology and adaptive evolution of a highly invasive pest species. Genome Biology 17: 192. https://doi.org/10.1186/s13059-016-1049-2

Papathanos, P. A., K. Bourtzis, F. Tripet, H. Bossin, J. F. Virginio, M. L. Capurro, M. C. Pedrosa, A. Guindo, L. Sylla, M. B. Coulibaly, F. A. Yao, P. S. Epopa, and A. Diabate. 2018. A perspective on the need and current status of efficient sex separation methods for mosquito genetic control. Parasites and Vectors 11 (Suppl. 2): 654. https://doi.org/10.1186/s13071-018-3222-9

Rendón, P., D. McInnis, D. Lance, and J. Stewart. 2000. Comparison of medfly male-only and bisexual releases in large scale field trials, pp. 517-525. In K. H. Tan (ed.), Proceedings: Area-Wide Control of Fruit Flies and Other Insect Pests. International Conference on Area-Wide Control of Insect Pests, and the $5^{\text {th }}$ International Symposium on Fruit Flies of Economic Importance, 28 May-5 June 1998, Penang, Malaysia. Penerbit Universiti Sains Malaysia, Pulau Pinang, Malaysia. http://www-naweb.iaea.org/nafa/ipc/public/Area-wide-control_491-650.pdf

Rendón, P., D. McInnis, D. Lance, and J. Stewart. 2004. Medfly (Diptera: Tephritidae) genetic sexing: large-scale field comparison of males-only and bisexual sterile fly releases in Guatemala. Journal of Economic Entomology 97: 1547-1553. https://doi.org/10.1603/0022-0493-97.5.1547

Robinson, A. S. 2002. Mutations and their use in insect control. Mutation Research (Reviews in Mutation Research) 511: 113-132. https://doi.org/10.1016/S1383-5742(02)00006-6

Robinson, A. S., and G. Franz. 2000. The application of transgenic insect technology in the sterile insect technique, pp. 307-318. In A. M. Handler and A. A. James (eds.), Insect transgenesis: methods and application. CRC Press, Boca Raton, FL, USA. 
Robinson, A. S., and C. Van Heemert. 1982. Ceratitis capitata - a suitable case for genetic sexing. Genetica 58: 229-237. https://link.springer.com/article/10.1007/BF00128017

Robinson, A. S., G. Franz, and K. Fisher. 1999. Genetic sexing strains in the medfly, Ceratitis capitata: development, mass rearing and field application. Trends in Entomology 2: 81-104. http://www.researchtrends.net/tia/abstract.asp?in=0\&vn=2\&tid=20\&aid=684\&pub=1999\&type=

Robinson, A. S., G. Franz, and P. W. Atkinson. 2004. Insect transgenesis and its potential role in agriculture and human health. Insect Biochemistry and Molecular Biology 34: 113-120. https://doi.org/10.1016/j.ibmb.2003.10.004

Rössler, Y. 1979. The genetics of the Mediterranean fruit fly: a "white pupae" mutant. Annals of the Entomological Society of America 72: 583-585. https://doi.org/10.1093/aesa/72.5.583

Rossler, Y., and H. Rosenthal. 1992. Genetics of the Mediterranean fruit fly (Diptera: Tephritidae): morphological mutants on chromosome five. Annals of the Entomological Society of America 85: 525531. https://doi.org/10.1093/aesa/85.4.525

Rössler, Y., A. Malacrida, and M. C. Zapater. 1994. Mutants, chromosomes, and genetic maps in the Mediterranean fruit fly, pp. 97-112. In C. O. Calkins, W. Klassen and P. Liedo (eds.), Fruit flies and the sterile insect technique. CRC Press, Boca Raton, FL, USA.

San Andrés, V., A. Urbaneja, B. Sabater-Muñoz, and P. Castañera. 2007. A novel molecular approach to assess mating success of sterile Ceratitis capitata (Diptera: Tephritidae) males in sterile insect technique programs. Journal of Economic Entomology 100: 1444-1449. https://doi.org/10.1093/jee/100.4.1444

Seawright, J. A., P. E. Kaiser, D. A. Dame, and C. S. Lofgren. 1978. Genetic method for the preferential elimination of females of Anopheles albimanus. Science 200(4347): 1303-1304. DOI: $10.1126 /$ science. 663614 http://science.sciencemag.org/content/200/4347/1303

Spanos, L., G. Koutroumbas, M. Kotsyfakis, and C. Louis. 2000. The mitochondrial genome of the Mediterranean fruit fly, Ceratitis capitata. Insect Molecular Biology 9: 139-144. https://doi.org/10.1046/j.1365-2583.2000.00165.x

Stratikopoulos E. E., A. A. Augustinos, Y. G. Petalas, M. N. Vrahatis, A. Mintzas, K. D. Mathiopoulos, and A. Zacharopoulou. 2008. An integrated genetic and cytogenetic map for the Mediterranean fruit fly, Ceratitis capitata, based on microsatellite and morphological markers. Genetica 133: 147-157. https://doi.org/10.1007/s10709-007-9195-9

Todd, T., P. Rendon, and R. Ruiz-Arce. 2017. Inheritance of fifteen microsatellite loci in Ceratitis capitata (Diptera: Tephritidae). Florida Entomologist 100: 77-91. https://doi.org/10.1653/024.100.0113

Whitten, M. J. 1969. Automated sexing of pupae and its usefulness in control by sterile insects. Journal of Economic Entomology 62: 271-273. https://doi.org/10.1093/jee/62.1.271a

Willhoeft, U., and G. Franz. 1996. Identification of the sex-determining region of the Ceratitis capitata $Y$ chromosome by deletion mapping. Genetics 144: 737-745. http://www.genetics.org/content/genetics/144/2/737.full.pdf

Yamada. H., S. M. Soliban, M. J. B. Vreysen, D. D. Chadee, and J. R. L. Gilles. 2013. Eliminating female Anopheles arabiensis by spiking blood meals with toxicants as a sex separation method in the context of the sterile insect technique. Parasites and Vectors 6: 197. https://doi.org/10.1186/1756-3305-6-197

Zacarés, M., G. Salvador-Herranz, D. Almenar, C. Tur, R. Argilés, K. Bourtzis, H. Bossin, and I. Pla. 2018. Exploring the potential of computer vision analysis of pupae size dimorphism for adaptive sex sorting systems of various vector mosquito species. Parasites and Vectors 11 (Suppl. 2): 656. https://doi.org/10.1186/s13071-018-3221-x

Zacharopoulou, A. 1987. Cytogenetic analysis of mitotic and salivary gland chromosomes in the medfly Ceratitis capitata. Genome 29: 67-71. https://doi.org/10.1139/g87-011

Zacharopoulou, A. 1990. Polytene chromosome maps in the medfly Ceratitis capitata. Genome 33: 184 197. https://doi.org/10.1139/g90-030 
Zacharopoulou, A., K. Bourtzis, and P. Kerremans. 1991. A comparison of polytene chromosomes in salivary glands and orbital bristle trichogen cells in Ceratitis capitata. Genome 34: 215-219. https://doi.org/10.1139/g91-034

Zepeda-Cisneros, C. S., J. S. Meza Hernández, V. García-Martínez, J. Ibañez-Palacios, A. Zacharopoulou, and G. Franz. 2014. Development, genetic and cytogenetic analyses of genetic sexing strains of the Mexican fruit fly, Anastrepha ludens Loew (Diptera: Tephritidae). BMC Genetics 15(Suppl. 2): S1. https://doi.org/10.1186/1471-2156-15-S2-S1 